\title{
Post-transcriptional regulation by cytosine-5 methylation of RNA
}

Raquel García-Vílchez ${ }^{1,4}$, Ana Sevilla ${ }^{2,4}$, Sandra Blanco ${ }^{1,3,5}$

${ }^{1} \mathrm{CIC}$ bioGUNE, Bizkaia technology park, 48160, Derio, Spain. ${ }^{2}$ Physiology, Cellular Biology and Immunology Department - Biology Faculty. University of Barcelona, Avda. Diagonal 643 08028 Barcelona. Spain. ${ }^{3}$ Molecular Mechanisms Program, Centro de Investigación del Cáncer and Instituto de Biología Molecular y Celular del Cáncer, Consejo Superior de Investigaciones Científicas (CSIC)-University of Salamanca, 37007 Salamanca, Spain.

${ }^{4}$ These authors contributed equally.

${ }^{5}$ Correspondence to: sandra.blanco@usal.es 


\begin{abstract}
The recent advent of high-throughput sequencing technologies coupled with RNA modifications detection methods has allowed the detection of RNA modifications at single nucleotide resolution giving a more comprehensive landscape of post-transcriptional gene regulation pathways. In this review, we focus on the occurrence of 5-methylcytosine $\left(\mathrm{m}^{5} \mathrm{C}\right)$ in the transcriptome. We summarise the main findings of the molecular role in posttranscriptional regulation that governs $\mathrm{m}^{5} \mathrm{C}$ deposition in RNAs. Functionally, $\mathrm{m}^{5} \mathrm{C}$ deposition can regulate several cellular and physiological processes including development, differentiation and survival to stress stimuli. Despite many aspects concerning $\mathrm{m}^{5} \mathrm{C}$ deposition in RNA, such as position or sequence context, and the fact that many readers and erasers still remain elusive, the overall recent findings indicate that RNA cytosine methylation is a powerful mechanism to post-transcriptionally regulate physiological processes. In addition, mutations in RNA cytosine-5 methyltransferases are associated to pathological processes ranging from neurological syndromes to cancer.
\end{abstract}

\title{
Keywords
}

5-methylcytosine, 5-hydroxymethylcytosine, RNA methylation, epitranscriptome, posttranscriptional regulation, translation. 


\section{Introduction}

The first modified RNA nucleoside was identified almost 60 years ago and since then around 171 distinct modified nucleotides have been characterized. Most of them are located at abundant non-coding RNAs such as transfer RNAs (tRNAs) from all kingdoms of life [1]. Initial detection studies were based on chromatography techniques and thus were largely limited to detect only more abundant modifications in more stable and abundant RNAs and with little information on their distribution. The presence of chemical modifications on messenger RNA (mRNA) was uncovered in the 70's, when poly-A tail-based purification techniques first allowed for pure mRNA preparations to rule out contamination with other RNA species [2]. These studies identified the existence of internal RNA modifications including $\mathrm{N}^{6}$-methyladenosine $\left(\mathrm{m}^{6} \mathrm{~A}\right)$ and 5-methylcytosine $\left(\mathrm{m}^{5} \mathrm{C}\right)$ [2].

However, despite the identification of cytosine- 5 methylation in RNA and DNA more than 40 years ago, we are still now beginning to understand its function in RNA and most of our knowledge on cytosine-5 methylation has focused on DNA. Initial reports on the methylation of ribosomal RNA ( $r R N A$ ) showed that rRNA presented specific patterns with regards to their type of methylation, being the $28 \mathrm{~S}$ molecules mainly ribose-methylated and 18S rRNA basemethylated [3]. Subsequent studies concluded that methylation of bases was more conserved and present in bacteria and eukaryotes, whereas ribose methylation appeared in eukaryotic cells (extensively reviewed in [4]). Shortly after the discovery of nucleotide methylation in the cap-structure of eukaryotic mRNAs, some studies arose showing the presence of methylated nucleotides in mRNAs in mammalian cells [2] and viral RNAs, including $\mathrm{m}^{5} \mathrm{C}$ [5]. However other studies did not find $\mathrm{m}^{5} \mathrm{C}$ deposition in human mRNAs [6].

While 5-methylcytidine is best known for its central role as an epigenetic mark in DNA, the study of its functional role in RNA is only beginning to emerge. Lately, with the venue of new technological advances in sequencing, special focus has been recovered on detecting RNA modifications. Recent attempts of high throughput detection methods have revealed $\mathrm{m}^{5} \mathrm{C}$ occurrence in coding and non-coding RNAs [7-13]. In addition, the functional roles of $\mathrm{m}^{5} \mathrm{C}$ and other RNA modifications have begun to be elucidated, as well as their writers (enzymes that catalyse their deposition), erasers (enzymes that catalyse their removal) and readers (RNA-binding proteins that specifically bind to RNA modifications) have been identified. It is becoming increasingly clear that the epitranscriptome landscape is highly encoded and it is likely to play many critical functions of RNA metabolism as well as cellular processes including proliferation, differentiation or development. 
In this review, we summarise the current knowledge on cytosine-5 RNA methylation distribution in all RNA classes, with special emphasis on the latest advances in $m^{5} \mathrm{C}$ deposition and function in eukaryotes. We review system-wide available methods for detection of $\mathrm{m}^{5} \mathrm{C}$ sites at nucleotide resolution and discuss their advantages and limitations. We describe the cytosine methyltransferases known so far, the protein readers as well as the recent findings on 5-hydroxymethylcytosine occurrence in RNA. We then examine the molecular role of this modification in RNA metabolism and processing, and emphasise the functional role in expression regulation and protein synthesis. Finally, we discuss the physiological role and the pathological implications of its dysregulation in diseases and analyse the remaining challenges in determining the functions of RNA $\mathrm{m}^{5} \mathrm{C}$ deposition.

\section{RNA Cytosine-5 methylation sequencing detection methods}

The existence of $\mathrm{m}^{5} \mathrm{C}$ in RNAs has been known since the 1970s [2, 5]. However, its occurrence in low abundance RNAs and its transcriptome-wide distribution have been difficult to determine due to the lack of reliable and sensitive methods to detect $\mathrm{m}^{5} \mathrm{C}$ at nucleoside resolution. The recent advances in next-generation sequencing (NGS) tools have made possible the development of sequencing technologies that have provided a comprehensive view of $\mathrm{m}^{5} \mathrm{C}$ distribution patterns throughout the global transcriptome. These methods have also allowed the definition of the dynamic epitranscriptomic status under different physiological conditions, as well as the characterization of each of the specific substrates of currently known RNA methyltransferases.

Several high throughput $\mathrm{m}^{5} \mathrm{C}$ detection methods have been developed so far. Generally, their methodologies are based on immunoprecipitation techniques, chemical conversion of the modified base or a combination of both. Bisulphite sequencing exploits the chemical reactivity principles of cytosines and it has been widely used [14] (Fig. 1). Other currently used detection techniques are $m^{5} \mathrm{C}$ RNA immunoprecipitation ( $\left.{ }^{5} \mathrm{C}-\mathrm{RIP}\right)$ [10], 5-azacytidinemediated RNA immunoprecipitation (Aza-IP) [15], or methylation-individual nucleotide resolution crosslinking immunoprecipitation (miCLIP) [16]. These three methods are based on immunoprecipitation (IP) protocols and allow for the enrichment of low abundance $\mathrm{m}^{5} \mathrm{C}$ modified RNAs. These IP-based techniques have overcome some of the limitations of bisulphite sequencing discussed here, including enrichment for low abundance RNAs or RNAs with low $\mathrm{m}^{5} \mathrm{C}$ content. Additionally, Aza-IP and miCLIP enable the identification of enzyme-specific targets. In the following section, we will discuss the methodological approach as well as the advantages and limitations of each of the $\mathrm{m}^{5} \mathrm{C}$ detection sequencing 
techniques. Other non-sequencing based approaches that have allowed the detection of $\mathrm{m}^{5} \mathrm{C}$ in RNA since its initial discovery are extensively reviewed elsewhere [17].

\subsection{Bisulphite sequencing}

Bisulphite conversion protocols were initially developed to detect $m^{5} \mathrm{C}$ in DNA [18], and later adapted to detect $\mathrm{m}^{5} \mathrm{C}$ in RNA [19]. By coupling bisulphite conversion protocols to high throughput sequencing techniques, Schaefer and colleagues determined the distribution of $\mathrm{m}^{5} \mathrm{C}$ throughout Drosophila tRNAs and rRNAs [14]. Three years later, the protocol was successfully applied at transcriptome-wide level providing the first global view of the $\mathrm{m}^{5} \mathrm{C}$ methylome in human RNAs at single nucleotide resolution [11]. The technique relies on the differential chemical reactivity of unmethylated and methylated cytosines (C). Unmethylated Cs are converted into uraciles $(U)$ by deamination in the presence of sodium bisulphite. Meanwhile, methylated Cs and double stranded nucleotides are protected from deamination. The extent of modifications at each cytosine residue is then determined by calculating the fraction of reads that do not show the expected $C$ to $U$ change, assuming complete conversion of unmethylated C (Fig. 1). Bisulphite sequencing is the gold standard and it has allowed the identification of $\mathrm{m}^{5} \mathrm{C}$ deposition in RNA at single nucleotide resolution in cells in culture and in vivo and the validation of methylases specific targets $[8-13,20,21]$. The biggest advantages of the technique are its high specificity to detect modified cytosines throughout the transcriptome and its single nucleotide resolution. Yet, it has several limitations: although the chemical conversion is highly specific to cytosines, the sites could include other cytosine modifications that interfere with bisulphite conversion such as 3methylcytosine and 5-hydroxymethylcytosine among others (reviewed in [22]). Highly structured RNA regions difficult to denature are also protected from the conversion reaction (reviewed in [22]). In addition, its application is limited only for highly abundant RNA molecules, due to the loss of RNA by chemical hydrolysis caused by the harsh conditions (denaturation at high temperature, low $\mathrm{pH}$ conditions) during the long bisulphite conversion process. This may explain why the use of bisulphite sequencing has resulted in marked differences in the reported prevalence of $\mathrm{m}^{5} \mathrm{C}$ in low abundance RNAs. For example, from thousand $\mathrm{m}^{5} \mathrm{C}$ sites in mRNA in HeLa cells compared to fewer mRNAs in other cell types or tissues $[11,12]$. Therefore, the technique is somehow erratic to detect $\mathrm{m}^{5} \mathrm{C}$ in low abundance RNAs or highly structured RNAs. Increased strand denaturation by using denaturing agents (formamide), random fragmentation of RNA or enrichment of low abundance RNAs can overcome some of the technical limitations [12, 23]. Yet, the technique does not reveal information about substrate specificity and requires genetic manipulation of RNA methylases to reveal methylase-specific positions. In addition, despite 
all the advances, analyses of $\mathrm{m}^{5} \mathrm{C}$ deposition in low abundance RNAs have resulted in annotation discrepancies indicating that $\mathrm{m}^{5} \mathrm{C}$ detection by bisulphite sequencing still remains a difficult task [24]. In fact, it requires statistically robust and highly refined bioinformatic tools to allow for a reliable analysis of the RNA methylome.

\section{2. $m^{5} \mathrm{C}$ RNA immunoprecipitation}

$\mathrm{m}^{5} \mathrm{C}$-RIP exploits the use of antibodies that bind to 5-methylcytosine followed by library preparation of enriched $\mathrm{m}^{5} \mathrm{C}$-modified RNAs and high throughput sequencing. This approach was used to map $\mathrm{m}^{5} \mathrm{C}$-modified RNAs in bacteria, Archaea, yeast and plants transcriptome $[9,10] . m^{5} C-R I P$ overcomes some of the pitfalls derived from bisulphite sequencing such as the hydrolysing conditions during bisulphite conversion protocol, and thus reducing the degradation of low abundance RNAs. Yet, the biggest caveat is the high dependency on the antibody specificity. Furthermore, this protocol relies on RNA-antibody complexes that are non-covalently bound, and thus purification of RNA molecules is performed in low stringency conditions increasing the risk of purifying non-specifically bound RNAs. To overcome these issues and truly define enzyme-specific $\mathrm{m}^{5} \mathrm{C}$ deposition, one can combine this protocol with genetic deletion or knock-down of RNA methylases and RNA-protein cross-linking approaches [25].

\subsection{5-azacytidine-mediated RNA immunoprecipitation}

Aza-IP allows the detection of enzyme-specific methylation sites [15]. Aza-IP is based in the use of 5-azacytidine (5-aza-C), a cytidine analogue that forms a stable link between the enzyme and the RNA substrate, preventing the separation of both components [15]. 5-aza-C is fed into cells and randomly incorporated into the nascent RNA transcripts at $C$ positions. The cytidine analogue traps the methylase forming a covalent adduct. Covalently bound RNA-methylase complexes are immunoprecipitated with enzyme-specific or tag antibodies. Next, the RNA is released from the methylase-RNA complex, triggering a hydrolytic opening of the 5-aza-C ring which is read as a guanine during reverse transcription and sequencing [15] (Fig. 1). This approach enables base-resolution mapping of the target sites in RNA. One of its biggest advantages is that $\mathrm{m}^{5} \mathrm{C}$-modified RNAs are covalently bound to the methylase under study, and the RNA-protein complexes can be purified under high stringency conditions, thus reducing the background of non-specific bound RNAs. Thus, the technique relies on highly specific antibodies against the investigated methylase or the use of genetically engineered cell lines or model organisms that stably expressed a tagged version of the enzyme. Yet, the biggest limitation is the random incorporation of 5-azacytidine and $\mathrm{m}^{5} \mathrm{C}$ sites that are not replaced by 5 -azacytidine will be missed. Additionally, the cytidine 
analogue is highly toxic, it can be also incorporated into DNA and disrupt the normal transcriptional processes as well as DNA and RNA integrity.

\subsection{Methylation-individual nucleotide resolution crosslinking immunoprecipitation}

miCLIP follows the same principle as Aza-IP with the difference of its genetic base. This strategy combines individual nucleotide resolution crosslinking and immunoprecipitation (iCLIP) approach to genetic engineering approaches allowing the identification of methylase specific deposition sites with nucleotide resolution [16]. The technique was first used to identify methylation substrates of NSUN2 by exploiting the structural and functional properties of the catalytic domain of NSUN members [16]. A mutation of a conserved cysteine at the catalytic domain $(\mathrm{C} 271 \mathrm{~A})$ that releases the RNA from the enzyme led to the establishment of covalently bound RNA-substrates [16, 26]. Methylation positions can be determined because protein crosslinking to the target cytosines lead to termination of reverse transcription during library preparation [16]. This strategy was later used to identify NSUN3 substrates [21]. Despite being a very robust method with high specificity, the technique has limitations too. For instance, cells or organisms expressing the mutant enzymes need to be generated by genetic engineering techniques which increases the time and cost of its performance. In addition, expression of mutant enzymes may produce star activity which could result in the detection of non-bona fide substrates.

In conclusion, all the currently available sequencing techniques show different caveats caused by a variety of reasons ranging from the experimental procedure to the data analysis approaches. This suggests the combinatorial use of different methods and the implementation of different computational strategies to produce a more robust and reliable picture of $\mathrm{m}^{5} \mathrm{C}$ methylomes.

\section{Cytosine-5 methylation distribution and cytosine-5 methyltransferases}

$\mathrm{m}^{5} \mathrm{C}$ is a conserved and prevalent mark in RNA in all life domains [1]. Yet, its occurrence and prevalence varies among RNA types and organisms. While $m^{5} \mathrm{C}$ has been found in tRNA and mRNA from eukaryotes and archaea, it is missing in tRNA and mRNA from prokaryotes $[1,2,7,9-12,20,27,28] . m^{5} \mathrm{C}$ deposition is catalysed by RNA $m^{5} \mathrm{C}$ methyltransferases (RCMTs) that belong to the superfamily of Rossman fold-containing enzymes that use S-adenosyl-L-methionine (SAM) as a methyl group donor. To date all confirmed eukaryotic $\mathrm{m}^{5} \mathrm{C}$-specific RNA methyltransferases belong to either the NOL1/NOP2/sun (Nsun) subgroups of methyltransferases or the DNA methyltransferase member DNMT2 (also known as TRNA Aspartic Acid Methyltransferase 1 or TRDMT1) (Fig. 
2) $[17,29]$. Below we will examine $m^{5} \mathrm{C}$ occurrence and distribution in each type of RNAs in eukaryotes, as well as the currently known methyltransferases that specifically target them.

\subsection{Cytosine-5 methylation in tRNAs}

$\mathrm{m}^{5} \mathrm{C}$ deposition in tRNAs is structure- and enzyme-specific. It is mostly found at conserved positions at cytosines at the junction of the variable loop and the $T$ stem spanning positions 48-50 of majority of tRNAs. It is also found at the anti-codon loop at positions 34 and 38 and at the acceptor arm at position 72 of fewer tRNAs [10, 11, 13, 16, 28, 30, 31] (Fig. 2). DNMT2, NSUN2, NSUN3 and NSUN6 all methylate tRNAs, yet with different specificity [8, $13,21,31-36]$. The best characterized RNA cytosine-5 methyltransferases in eukaryotes are DNMT2 and NSUN2 [8, 13, 16, 32, 33, 37-48]. NSUN2 methylates the majority of the cytoplasmic tRNAs at the variable loop at position 48-50, and leucine at position C34 at the anti-codon loop in mammals $[8,15,16]$. Likewise, NSUN2 yeast homologue Trm4 and Arabidopsis homologue TRM4B methylate similar positions indicating a highly conserved functional role $[9,20,28,30,31]$. NSUN6 targets $C 72$ at the acceptor stem of cysteine and threonine cytosolic tRNAs [35]. Meanwhile, mammalian NSUN3 catalyses the formation of $\mathrm{m}^{5} \mathrm{C}$ at position $\mathrm{C} 34$ of mitochondrial methionine tRNAs [21, 34, 36]. DNMT2-mediated methylation is restricted to three cytoplasmic tRNAs (Asp, Gly and Val) at position C38 at the anti-codon loop in mammals and Drosophila [13, 32, 37]. In comparison, fission yeast homologue Pmt1, Dictyostelium discoideum homologue DnmA and plant TRDMT1 all methylate tRNAs at the anti-codon loop [20, 49, 50].

\subsection{Cytosine-5 methylation in rRNAs}

Cytosine- 5 methylation in rRNA is the most conserved across all forms of life and thus reflecting its biological significance (Fig. 2) [1]. The nuclear large subunit 25S rRNA in yeast and $28 \mathrm{~S}$ rRNA in high eukaryotes contains two $\mathrm{m}^{5} \mathrm{C}$ sites that cluster around conserved structural and functional ribosome regions, suggesting functional relevance [51, 52]. NOP2 and the yeast homologue Nop2 catalyses the transfer of a methyl group onto C2870, which resides close to the peptidyltransferase center of the 28S rRNA (25S rRNA in yeast) of the large ribosomal subunit [27, 31, 52]. NSUN5, and the yeast homologue Rcm1, methylate position C2278 of 28S rRNA (and 25S rRNA in yeast), located at the interface between large and small subunit $[27,31,52]$. NSUN4 targets C911 on the small subunit $12 \mathrm{~S}$ of mitochondrial rRNA [53].

\subsection{Cytosine- 5 methylation in $m R N A s$}


The existence of $\mathrm{m}^{5} \mathrm{C}$ in eukaryotic mRNA has been difficult to prove due to its low prevalence and the lack of effective detection techniques. By using mass spectrometry, early studies in the 1970's, detected $\mathrm{m}^{5} \mathrm{C}$ in mammalian mRNAs [2], although some other studies failed to do so [6,54]. In recent years, advanced and more sensitive high performance liquid chromatography coupled to mass spectrometry (LC-MS) methods allowed the detection of $\mathrm{m}^{5} \mathrm{C}$ in mRNAs and thus ratifying that indeed mRNA is methylated at cytosines [55-57]. In addition, high throughput detection methods coupled to RNA sequencing have allowed the detection of $\mathrm{m}^{5} \mathrm{C}$ at single nucleotide resolution $[7,9,11,12,20]$. For instance, following bisulphite sequencing of total RNA from human HeLa cells, Squires and co-workers found 10275 methylated positions in the transcriptome and about 8000 sites were located in mRNA sequences [11]. Likewise, by using bisulphite sequencing of poly-A-enriched RNAs of the same cell line, 2000 mRNAs were found to be methylated [12]. In addition, bisulphite sequencing of poly-A-enriched RNAs from mouse tissues including brain, and from mouse embryonic stem cells (ESC) revealed few thousand mRNAs being methylated [7]. Regarding its $\mathrm{m}^{5} \mathrm{C}$ sites distribution, several studies have identified $\mathrm{m}^{5} \mathrm{C}$ deposition in different mRNA positions including 3' and 5' UTRs regions, at CDS (coding sequence) [7, 9, 11, 12, 16, 20]. In contrast, by using more stringent quality controls, tailored filters for sequencing and alignment artefacts and statistical modelling to eliminate non-conversion artefacts, Lyko and co-workers could not identify any clear $\mathrm{m}^{5} \mathrm{C}$ site in mouse mRNAs [24].

Attempts to detect $\mathrm{m}^{5} \mathrm{C}$ in mRNA from other species have identified methylated mRNAs in various plant species $[9,10,20]$. By using bisulphite sequencing, $m^{5} \mathrm{C}-\mathrm{RIP}$-seq and liquid chromatography coupled with tandem mass spectrometry (LC-MS/MS), $\mathrm{m}^{5} \mathrm{C}$ residues were detected in mRNA from different plant organs [9, 20]. One study found 100 sites and enrichment at 3'UTR [20] and the other reported more than $6000 \mathrm{~m}^{5} \mathrm{C}$ sites and enriched in the CDS [9]. Combining bisulphite sequencing and $m^{5} \mathrm{C}$-RIP-seq approaches on archaebacteria, bacteria and budding yeast mRNAs, Sorek and colleagues identified $\mathrm{m}^{5} \mathrm{C}$ residues only in archaeal mRNAs, although at very low prevalence [10]. $\mathrm{m}^{5} \mathrm{C}$ residues have not been detected in Drosophila mRNAs [24].

Attempts to determine the specific writers of $m^{5} \mathrm{C}$ in mRNA have indicated that human NSUN2 and its homologue in plants TRM4B are currently the only cytosine-C5 methylases with capacity to modify mRNAs (Fig. 2) [9, 11, 12, 16, 20]. Whether other cytosine-5 methyltransferases target mRNA remains unknown. 
Overall, multiple lines of evidence show that mRNA is methylated [7, 10-12, 55-57], yet its prevalence and site distribution in mRNA still remain elusive.

\subsection{Cytosine-5 methylation in other non-coding RNAs}

$\mathrm{m}^{5} \mathrm{C}$ has also been detected in small non-coding RNAs and long non-coding RNAs (IncRNA) $[9,11,15,16,20,58]$. Bisulphite sequencing on polyA-RNAs from several human cell lines identified $\mathrm{m}^{5} \mathrm{C}$ sites within or near functionally important regions of IncRNAs HOTAIR and XIST [58]. Using bisulphite sequencing, miCLIP and Aza-IP for human NSUN2, $\mathrm{m}^{5} \mathrm{C}$ sites were identified in the three vault RNAs (vtRNA) vtRNA1.1, vtRNA1.2 and vtRNA1.3 $[15,16]$. In addition, NSUN2-mediated methylation sites were identified in Ribonuclease P RNA component H1 (RPPH1), 5S rRNA, the C/D box small nucleolar (snoRNA) small cajal body specific RNA 2 (SCARNA2), RNY1, signal recognition particle RNA (7SL RNA) and the small nuclear RNA 7SK $[11,15,16]$. Although the number of methylated ncRNAs that have been described so far is still small, most are methylated by NSUN2. These results indicate that mammalian NSUN2 is currently the cytosine-C5 methylase with a broader substrate specificity as it methylates ncRNAs, tRNAs and mRNAs $[8,11,12,15,16]$. Similar to human NSUN2, plant TRM4B methylates a wide range of non-coding RNAs including small nuclear RNAs, snoRNAs and IncRNAs [20].

Another NSUN family member with affinity for ncRNAs is NSUN7. NSUN7 was described to interact with the transcriptional coregulator peroxisome proliferator-activated receptorgamma coactivator 1 alpha (PGC-1 $\alpha$ ) and with promoter-derived enhancer RNAs (eRNAs) of several PGC-1 $\alpha$ target genes in mouse hepatocytes (Fig. 2) [59]. Bisulphite conversion and Aza-IP experiments followed by qPCR of eRNAs from cells depleted of Nsun7 showed a decrease of the presence of $\mathrm{m}^{5} \mathrm{C}$ sites, suggesting that eRNAs selectively undergo cytosine methylation [59]. The report further showed that NSun7 expression and $\mathrm{m}^{5} \mathrm{C}$ content on RNA increased after fasting, suggesting that both events were regulated upon metabolic stress [59].

\section{Functional role of cytosine-5 methylation}

Early studies in single cell organisms shed light on the molecular and biological functions of $\mathrm{m}^{5} \mathrm{C}$ methylases indicating multiple roles stabilizing tRNA molecules and in mRNA decoding [60-62]. In this section, we will discuss the biological roles associated to known methyltransferases, focusing mainly on eukaryotic organisms, as well as the molecular role of $\mathrm{m}^{5} \mathrm{C}$ in each RNA type. 


\subsection{Molecular and physiological role of NSUN2}

Cytosine- 5 methylation of tRNAs by NSUN2 has been linked to survival, differentiation and development in eukaryotes [8, 9, 20, 30, 31, 43, 46-48, 63]. In humans and mice, comparative results of gene expression data with global cytosine-5 RNA methylome from Nsun2-deficient cells and tissues elucidated that loss of NSUN2-mediated tRNA methylation increased angiogenin-mediated endonucleolytic cleavage of tRNAs [8]. Consequently, Nsun2-deficient cells aberrantly accumulated $5^{\prime}$ tRNA-derived small RNA fragments (5' tRFs) [8]. Molecularly, accumulation of $5^{\prime}$ tRFs resulted in global repression of protein translation (Fig. 3A). Ribosome profiling studies further showed a favoured increased translation of mRNAs encoding for stress response genes [47]. The study, similar to previous works in yeast [30], linked NSUN2-mediated RNA methylation to stress-specific reprogramming of translation and demonstrated that translational control through RNA methylation is a conserved stress survival mechanism. Consequently, Nsun2-deficient cells were hypersensitive to stress $[8,47]$. Likewise, Trm4B loss in plants (Nsun2 homologue in plants) resulted in increased sensitivity to oxidative stress [9, 20], and double null mutants trm4B trdmt1 were hypersensitive to the antibiotic hygromycin B [31]. Altogether, demonstrating a function of RNA methylation in regulating stress responses and survival.

Studies in mice also revealed that lack of NSUN2-mediated RNA methylation repressed the translation of transcripts encoding for differentiation genes in mammals [47]. Consequently, loss of Nsun2 in mouse led to differentiation failure, causing developmental delayed and tissue differentiation defects in mice [8, 43, 46, 48]. For instance, deletion of Nsun2 in mice decreased differentiation of hair follicle stem cells and germ cells leading to hair growth defects and infertility in male mice [43,46]. Likewise, loss of Nsun2 in mice caused accumulation of intermediate progenitors and a decrease in differentiated upper-layer neurons in the cortex due to decreased differentiation and migration of neural progenitors [48]. Together these indicate that NSUN2-mediated RNA methylation regulates developmental and differentiation processes. Not surprisingly, NSUN2 was initially described as a downstream target gene of Myc in a population of progenitor and differentiating cells in human and mouse epidermis [64]. NSUN2 expression was also shown to be highest during embryo development in ectodermal tissues and in the compartment of differentiating cells in adult tissues [43, 46, 48, 65].

NSUN2 also targets other non-coding RNAs such as vault RNAs. Molecularly, loss of NSUN2 in human cells induces cleavage of vault RNAs into small RNAs that interfere with 
the silencing machinery (Fig. 3B) [16]. Nevertheless, the physiological significance of NSUN2-mediated methylation of vault RNAs or other non-coding RNAs remains elusive.

\subsection{Molecular role of the RNA methyltransferase NSUN3}

NSUN3-mediated methylation of mitochondrial methionine tRNA at position C34 has been shown to be further oxidized by the alphaketoglutarate and $\mathrm{Fe}(\mathrm{II})$-dependent dioxygenase ALKBH1/ABH1 to generate 5 -formylcytidine $\left(f^{5} \mathrm{C}\right)$ at this position $[21,34,66]$. Functional studies in mice and humans showed that loss of NSUN3 and lack of formylated methionine tRNA resulted in reduced mitochondrial translation (Fig. 3D) [21, 34, 36, 67]. In addition, it was shown that catalytic inactivation of Nsun3 in mouse ESCs further caused impaired differentiation into the neuroectodermal lineages [67]. Nonetheless, the mechanistic link between the loss of mitochondrial methionine tRNA formylation and the impairment of differentiation remains unknown.

\subsection{Molecular role of the RNA methyltransferase NSUN6}

NSUN6 methylates two cytosolic tRNAs at C72 at the acceptor stem of only mature tRNAs [35]. The molecular and functional role of NSUN6-mediated methylation at tRNAs is unknown. However, its proximity to the amino acid charging position suggests a role in accurate discrimination of amino acids by the aminoacyl-tRNA synthetases and ultimately accurate protein synthesis. Whether NSUN6 has a broader substrate specificity and can target other RNA types remains unknown.

\subsection{Functional role of the rRNA methyltransferases NOP2, NSUN4, NSUN5}

Several studies have indicated that cytosine- 5 methyltransferases that target rRNA play a role in rRNA biogenesis and ribosome assembly. For instance, functional studies in mouse showed that the mitochondrial family member NSUN4 was required for the methylation of 12S rRNA of the mitochondrial small ribosomal subunit and also to interact with MTERF4 facilitating the assembly of the large subunit (Fig. 3D) [53]. Likewise, functional studies in eukaryotic cells showed that lack of the rRNA methyltransferase targeting these positions, NOP2 and NSUN5, led to defects in ribosome biogenesis and assembly [27, 52, 68]. Studies in yeast further showed that Nop2p interaction, regardless of its methylation activity, was required for pre-rRNA processing [27, 69]. In addition, polysome profiling of Rcm1 null mutant in yeasts showed an increased in translation of transcripts encoding stress response genes (Fig. 3C) [70]. All together, these studies show that NSUN members with rRNA specificity possess two related functions in rRNA processing: an essential factor for pre- 
rRNA processing and methylation activity. The first supports the notion of quality control during ribosome synthesis by such enzymes [27, 53,68]. The second suggests that the occurrence of $\mathrm{m}^{5} \mathrm{C}$ could directly influence ribosomal activity to favour translational programmes in response to environmental changes [70]. Nonetheless, fluctuations of the fraction of methylated cytosines in rRNA have not been described yet. However, profiling of other modifications in human rRNA (ribose 2'-O-methylation) has revealed a subset of sites showing variable levels of modification [71], suggesting a role of rRNA modifications in the specialisation of the translating machinery. Mechanistically, whether the level of modified residues can dictate the recruitment or displacement of the ribosome onto specific mRNAs is still elusive. However, studies on the mechanism of $80 \mathrm{~S}$ complex formation on cellular internal ribosome entry sites (IRES) elements have shown that the 2'-O-methylation status of rRNA impaired the assembly of the ribosome on IRES, indicating a role for rRNA modifications on cellular IRES-mediated translation regulation [72]. All these findings suggest that RNA modifications may play a role in mRNA-specific translation regulation by ribosome specialisation.

Functional studies have shown that cytosine-5 rRNA methyltransferases play roles in development, proliferation and cell survival processes. For example, NSUN4 is essential for embryonic development in the mouse [53]. Studies in yeasts showed that Nop2 (NOP2 homologue in yeast) and Rcm1 (NSUN5 homologue in yeast) null mutants were not lethal, however, rcm1 mutants were hypersensitive to anisomycin and oxidative stress [52, 70]. Human NOP2 functional role has been associated to cell cycle [73]. Whether the enzymatic activity of NOP2 is directly required to mediate these cellular processes remains unclear. In C. elegans and flies, deletion of Nsun5 increased the lifespan of both organisms, indicating a role of rRNA cytosine-5 methylation in aging through protein synthesis control [70]. The functional role of NSUN5 in mammals has yet to be determined. These findings indicate that rRNA cytosine-5 methyltransferases control stress responses and developmental programmes.

\subsection{Functional role of NSUN7}

Little is known on the functional role of this NSUN member. During embryogenesis NSUN7 is highly expressed in different mouse tissues, indicating a role in development [65]. Nsun7 mutations in adult male mice have shown to lead to infertility and impaired sperm motility and in male mice [74], however, the underlying molecular mechanism remains unknown. In a recent report, NSUN7 was found to interact with the transcriptional coactivator PGC-1a and promoter-derived eRNAs of PGC-1 $\alpha$ target genes (Fig. 3E) [59]. Furthermore, NSUN7 
knock-down in human cells reduced eRNAs levels as well as the mRNA levels of PGC-1a target genes, indicating a role of NSUN7 in gene expression regulation mechanisms [59].

\subsection{Functional role of DNMT2}

Although initial studies showed that Dnmt2-deficient mice, flies and plants were viable, fertile and morphologically indistinguishable from wild-type organisms [32]. Studies in the past decade have shown that methylation of C38 by DNMT2 plays a role in several processes including tRNA processing, translation accuracy, survival and differentiation [13, 33, 37-40, 75]. Studies in flies and mice have shown that molecularly, loss of Dnmt2 causes increased tRNA cleavage and decreased tRNA stability leading to erratic discrimination of nearcognate codons for Asp, Gly and Val codons (Fig. 3F) [13, 33]. In addition, studies in mice also showed that DNMT2-mediated methylation in Asp tRNA, stimulated amino acid charging of the tRNA in vitro and in vivo, facilitating translation of poly-Asp containing proteins [41]. Phenotypic studies demonstrated that the absence of the methyltransferase resulted in endochondral ossification, cardiac hypertrophy and hematopoietic system differentiation defects in mice [33, 76]. Morpholino knock-down of Dnmt2 in zebrafish embryos caused retina, liver and brain differentiation defects due to a failure to conduct late differentiation [40].

In addition to the role that DNMT2 plays in differentiation, several studies in Drosophila have described the significance of DNMT2 in other physiological processes including survival to stress, immunity, regulation of silencing pathways as well as regulation of silencing of mobile genetic elements $[13,38,39,75]$. Null mutations of Dnmt2 in adult flies resulted in increased stress-induced tRNA cleavage and reduction of viability of mutant flies under heat and oxidative stress conditions [13]. In addition, Dnmt2 mediated tRNA methylation contributed to the control of siRNA pathway components during the heat shock response [39]. This study showed that increased of tRNA-derived double stranded RNA fragments induced upon Dnmt2 loss, promoted their binding to Dicer-2. Consequently Dicer-2 complex activity was inhibited and resulted in misregulation of siRNA pathway-controlled gene expression (Fig. 4A) [39]. Interestingly, tRNA fragments can affect the efficiency of siRNA silencing pathways in human cells raising the possibility that tRNA-derived RNA fragments may play a role in gene silencing pathways in human cells too [77]. Because the activity of Dicer-2 is required for the production of virus-derived small-interfering RNAs, it is not surprising that Dnmt2 is also required for efficient innate immune responses in Drosophila [38]. In fact, infectious studies showed that lack of Dnmt2 resulted in increased levels of Drosophila $C$ virus in infected mutant flies. The study further showed that Dnmt2 efficiently regulated viral 
replication by binding to viral RNA (Fig. 4B) [38]. Another recently described phenotype in Dnmt2 and Nsun2 null mutant flies was the characteristic silencing defects of transposable elements and impaired chromatin formation (Fig. 4C) [75]. Schaefer and colleagues further showed reduced tRNA stability influenced the expression or metabolism of TE-derived sequences [75]. Whether Dnmt2 and Nsun2 can methylate transposable elements remains unknown.

In summary, although we are only now beginning to understand the physiological relevance of cytosine- 5 methylation in RNA, it is becoming clear that it represents a new layer of control for several cellular processes.

\section{Role of $m^{5} \mathrm{C}$ in $\mathrm{mRNAs}$}

The molecular role and physiological relevance of $\mathrm{m}^{5} \mathrm{C}$ occurrence in mRNA remains still elusive. Despite many recent advances, little is known on $\mathrm{m}^{5} \mathrm{C}$ deposition dynamics, site distribution or protein readers in mRNA. While some system-wide studies have analysed $\mathrm{m}^{5} \mathrm{C}$ site distribution on mRNA to gain insights on its molecular role, yet no defined consensus on the site distribution has been found $[7,9,11,12,16,20]$. Other studies have attempted to gain information about $\mathrm{m}^{5} \mathrm{C}$ physiological function by performing gene ontology (GO) term enrichment analyses of $\mathrm{m}^{5} \mathrm{C}$-modified mRNAs, yet any common GO term arose from those studies $[7,11,12]$. Likewise, a few studies have also investigated the contribution of $\mathrm{m}^{5} \mathrm{C}$ occurrence in mRNAs stability $[7,9,12]$. Generally, there was no correlation between mRNA expression levels and $m^{5} \mathrm{C}$ occurrence. In addition, few studies have analysed the correlation of $\mathrm{m}^{5} \mathrm{C}$ occurrence in mRNA with translation efficiency or accuracy. In vitro studies employing a bacterial translation system showed that, while single $\mathrm{m}^{5} \mathrm{C}$ modifications did not strongly inhibit protein synthesis independent of their localization within a codon, $\mathrm{m}^{5} \mathrm{C}$ led to a $4 \%$ mis-recoding of proline as leucine [78]. In eukaryotes, some reports have investigated the effect of $\mathrm{m}^{5} \mathrm{C}$ on translation of few single transcripts [79-81]. Yet nobody has reproduced these data requiring further validation. Thus, the effect on translation efficiency of methylated mRNAs still remains uncertain in eukaryotes.

Recently, it has been evidenced Aly/REF export factor as a mRNA-binding protein that recognises and binds $\mathrm{m}^{5} \mathrm{C}$-containing mRNAs [12]. The study further reported that Aly/REF knock-down resulted in increased nuclear retention of $\mathrm{m}^{5} \mathrm{C}$-modified mRNAs, an effect that was suppressed by overexpression of wild-type but not $\mathrm{m}^{5} \mathrm{C}$-binding defective Aly/REF. Thus, the study suggested a role for $m^{5} \mathrm{C}$ occurrence in mRNA export (Fig. 5) [12]. It is unknown whether Aly/REF is the only $m^{5} \mathrm{C}$ reader protein specific for mRNA and if the only 
molecular function of $\mathrm{m}^{5} \mathrm{C}$ in mRNAs is to favour their export. In addition, whether increased nuclear export of $\mathrm{m}^{5} \mathrm{C}$-containing mRNAs favours their translation or impacts their degradation in the cytoplasm remains uncertain and needs further evaluation.

Overall, while some studies have attempted to investigate the regulatory role of $\mathrm{m}^{5} \mathrm{C}$ in mRNA metabolism or fate, our knowledge is still very limited.

\section{Deposition and role of cytosine-5-hydroxymethylation and cytosine-5-formylation}

Similar to DNA, recent findings have shown that existing 5-methylcytosine in RNA can suffer subsequent modifications. For instance, $\mathrm{m}^{5} \mathrm{C}$ can be oxidized to generate cytosine-5hydroxymethylation $\left(\mathrm{hm}^{5} \mathrm{C}\right)$ in vitro and in vivo by enzymes of the ten-eleven translocator family (TET) (Fig. 6) [55, 82]. Mass spectrometry studies revealed low but significant levels of $\mathrm{hm}^{5} \mathrm{C}$ in mRNA, which is in consistence with the low abundance of the $\mathrm{m}^{5} \mathrm{C}$ modification overall detected in mRNA $[55,57,83]$. Regarding to $\mathrm{hm}^{5} \mathrm{C}$, the highest in vivo levels were found in mouse and human brain relative to other tissues [55, 57, 84]. These results indicate a specificity that is reminiscent of $\mathrm{hm}^{5} \mathrm{C}$ amounts in DNA [85], suggesting that the cellular environment or activity of TET enzymes may cause hyper 5-cytosine hydroxymethylation in both DNA and RNA.

Studies in humans have contributed to shed some light of the broader regulatory mechanisms of RNA hm ${ }^{5} \mathrm{C}$, in particular, the role that $\mathrm{hm}^{5} \mathrm{C}$ has on pathogen infection and endogenous retroviral control $[82,86]$. A recent study demonstrated that TET2-mediated oxidation of methylated cytosines in mRNAs, increased the binding of the editing enzyme ADAR-1 to hydroxymethylated mRNAs [82]. In particular, it was shown that ADAR-1 binding to SOCS3 mRNA increased its editing and degradation, resulting in increased myelopoiesis [82]. These findings indicated that immune responses are regulated through a very sophisticated mechanism combining modifications and editing of mRNAs. $\mathrm{hm}^{5} \mathrm{C}$ deposition in human cells was also found in transcripts derived from endogenous retroviruses integrated in the genome that are transcriptionally and epigenetically controlled via DNA and RNA hm ${ }^{5} \mathrm{C}$ deposition [86].

Thus, those studies have revealed a significant role of $\mathrm{hm}^{5} \mathrm{C}$ in mRNAs besides its low prevalence. Not surprisingly, $\mathrm{hm}^{5} \mathrm{C}$ occurs also in other species of RNA such as tRNAs, which show higher prevalence of $\mathrm{m}^{5} \mathrm{C}$ modification compared to mRNAs, and thus might be more likely to show higher prevalence of $\mathrm{hm}^{5} \mathrm{C}$ too. In tRNAs, in vitro and in vivo studies showed that Alkylation repair homologues family member $\mathrm{ALKBH} 1$ can first hydroxylate $\mathrm{m}^{5} \mathrm{C}$ 
to form $\mathrm{hm}{ }^{5} \mathrm{C}$, and subsequently oxidize $\mathrm{hm}^{5} \mathrm{C}$ to form 5 -formylcytosine $\left(\mathrm{f}^{5} \mathrm{C}\right.$ ) in leucine and methionine tRNA $[34,66]$. In particular, the $\mathrm{m}^{5} \mathrm{C}$-oxidation derivatives found in tRNAs are $\mathrm{hm}^{5} \mathrm{C}$ and $\mathrm{f}^{5} \mathrm{C}$ at position 34 in cytoplasmic leucine tRNA, and 5-formylcytosine at position 34 in mitochondrial methionine tRNA ( $\left.{ }^{5} \mathrm{C} 34 \mathrm{mt}-\mathrm{tRNA}\right)$, being this change driven by ALKBH1 $[34,66]$, instead of by the TET family members.

Finally, in vitro studies showed that TET1 enzyme can catalyse the formation of 5carboxylcytosine $\left(\mathrm{ca}^{5} \mathrm{C}\right)$ from existing $\mathrm{f}^{5} \mathrm{C}$ groups, however the RNA type was not specified (Fig. 6) [87].

Overall, the existence of $\mathrm{m}^{5} \mathrm{C}$-oxidized derivatives in RNA are just beginning to be appreciated and have been postulated to be equally dynamic as the reversible epigenetic marks previously reported on DNA. All these recent studies have demonstrated that while there is a broad repertoire of RNA and DNA cytosine-5 methylating enzymes, synthesis of $\mathrm{hm}^{5} \mathrm{C}$ is mediated by TET and ALKBH enzymes. This indicates that the very same TET enzymes that modify DNA can promiscuously target RNA, and therefore it is harder to discriminate DNA- or RNA-related biological functions.

\section{Pathologies associated to alterations in $m^{5} \mathrm{C}$ deposition}

In the last few years, our understanding about RNA cytosine-5 methylation pathways has significantly increased, indicating to be essential for a wide range of biological processes (Table 1). However, in some diseases, the precise molecular mechanisms and cellular processes regulated by these modifications need to be further studied to have a deeper knowledge and a better prognosis.

\subsection{NOP2}

NOP2 (also known as NSUN1 or p120) is a nucleolar protein and was initially found to be overexpressed in human cancer cell lines [88]. Its overexpression was shown to increase proliferation of mouse fibroblasts [73], and has been considered a prognostic marker for cancer cells with a high proliferative potential [89].

\subsection{NSUN2}

NSUN2 expression alterations have been also linked to several cancer types [64, 90, 91]. In fact, NSUN2 was initially described as a novel downstream target of Myc oncogene [64]. In 
addition, it is overexpressed in various solid tumours including breast, skin and colon [44, 64]. Initial studies showed that NSUN2 protein, regardless of its methyltransferase activity, was required for mitotic spindle stability, and its overexpression in cancer cells led to aberrant mitosis [45]. In mouse skin tumours, its expression was lower in tumour initiating or stem cell populations compare to cell populations with high differentiation potential and low self-renewal potential [47]. Consequently, Nsun2 deletion in mouse skin tumours led to increased tumour growth due to an increase on tumour initiating cells with high self-renewal capacity [47]. Thus, NSUN2 expression levels do not always correlate with good or poor overall survival [90-92]. The most intriguing was its role in cancer cell survival. Nsun2 deletion and reduced tRNA cytosine-5 methylation in mouse tumours were shown to increase the sensitivity of tumour cells to anti-cancer drugs [47]. This suggested the combination of conventional chemotherapeutic agents together with RNA methyltransferases inhibitors as most effective therapeutic strategies to reduce tumour growth.

With the venue of the NGS technologies, mutations in some NSUN member genes have been associated to other human diseases. Inactivating mutations in NSUN2 have been found associated to autosomal recessive intellectual disability syndromes in humans characterized by microcephaly and mental and growth retardation [93-97]. In most cases, NSUN2 mutations lead to protein loss or mis-localization, and thereby a loss of site-specific 5-cytosine methylation [93, 94]. For instance, a homozygous variant in an intronic region of the gene NSUN2 (chr. 5 base position 6,622,214 C>G; hg19), located one base pair upstream of the start of exon 6 , which abolishes the canonical splice acceptor site, led to a subsequent mRNA and protein loss [94]. The mutation was associated to Dubowitz-like syndrome, an autosomal recessive syndrome defined by microcephaly, intellectual disability, skin disorders like eczema, growth and peculiar facies [94]. Mechanistically, the neurological abnormalities were linked to hypomethylated tRNAs, increased angiogenin-induced tRNA cleavage and increased sensitive to stress of cells during development [8, 48, 94]. Indeed, treatment of Nsun2-/- mouse embryos during development with an angiogenin inhibitor rescued the brain development abnormalities [8, 48].

In addition, homozygous 1-bp deletion (c.915del) in NSUN2 gene has been associated to an autosomal syndrome defined by bilateral ptosis, hypotonia and facial features suggestive of Noonan syndrome [98]. The deletion resulted in a truncated NSUN2 transcript presumably degraded via the nonsense-mediated decay pathway [98]. 


\subsection{NSUN3}

Loss-of-function mutations in NSUN3 have been identified in patients with muscular weakness, combined developmental disability, microcephaly, failure to thrive, recurrent increased lactate levels in plasma, proximal accentuated, external ophthalmoplegia and convergence nystagmus [21]. Analysis of patient-derived fibroblasts exhibited severe defects in mitochondrial translation due to lack of mitochondrial tRNA 5-cytosine methylation, suggestive of mitochondrial respiratory chain complex deficiency and OXPHOS deficiency in skeletal muscle [21]. In addition, pathogenic mutations in methionine mt-tRNA that are associated with mitochondrial diseases were showed to significantly impaired $\mathrm{m}^{5} \mathrm{C} 34$ forming activity by NSUN3, strongly suggesting that pathological symptoms in patients harboring these mutations were due to decreased levels of $f^{5} \mathrm{C} 34$ [36].

\subsection{NSUN4}

Loss-of-function mutations in NSUN4 have not been identified in patients, however its deletion in the heart in mice causes mitochondrial cardiomyopathy due to mitochondrial impaired translation and mitochondrial dysfunction [53].

\subsection{NSUN5}

Although there are no mutations associated to NSUN5 gene, it is located in a genomic region deleted in patients with Williams-Beuren syndrome (WBS) [99]. WBS is associated to a contiguous gene deletion of approximately $1.5 \mathrm{Mb}$ at $7 q 11.23$. It is a complex developmental disorder characterized by intellectual disability and developmental delay, as well as craniofacial and cardiovascular abnormalities [100]. Whether deletion of NSUN5 directly contributes to these symptoms is unknown.

\subsection{NSUN7}

A deletion of adenine in location 11337 in exon 4 and a T26248G-transversion mutation in exon7 of the NSUN7 gene were found in infertile men with reduced sperm motility [101, 102]. The A11337-deletion resulted in a TAG-early stop codon, and reduced, leading to a shorter protein product and reduced binding capacity to the S-adenosyl-I-methionine cofactor [101]. Whether defects on NSUN7 methylation activity can cause infertility is unknown.

\subsection{DNMT2}


DNMT2 has also been found consistently up-regulated in hundreds of tumour samples listed in the COSMIC database and 60 somatic mutations in DNMT2 have been identified in tumours originated from various tissues [103]. To investigate whether the mutations found cancer tissues had a functional effect in the activity of the enzyme, 13 mutations were selected and the mutant proteins were generated. One of the mutations (E63K) caused a twofold increase in activity, two of them led to a strong decrease in activity (G155S and L257V), and two additional mutant proteins were almost inactive (R371H and G155V). The strong effect of some of the somatic cancer mutations on DNMT2 activity suggests that these mutations have a functional role in tumorigenesis although further investigation is needed.

In summary, although the precise molecular and biological functions of RNA $\mathrm{m}^{5} \mathrm{C}$ methyltransferases are still poorly understood, there is a high number of alterations in NSUN-proteins associated with human disease syndromes. The diseased phenotypes associated to the alterations in the cytosine- 5 methylation machinery are diverse ranging from growth retardation, neurological deficits, muscular weakness, mitochondrial diseases, sterility or tumorigenesis, indicating that cytosine- 5 methylation is physiologically highly relevant in human health. Mutations or protein expression alterations of NSUN4 and NSUN6 have been associated to human diseases.

\section{Conclusion and future directions}

While modifications have long been known to be present in RNA, over the last six years there has been a renewed focus on the study of RNA modifications. Yet despite all of the latest advances, our knowledge about $\mathrm{m}^{5} \mathrm{C}$ in RNA is still in its infancy and many questions remain open. For instance, $\mathrm{m}^{5} \mathrm{C}$ site distributions and prevalence in low abundance RNAs such as mRNAs are still vague. The variable results on $m^{5} \mathrm{C}$ distribution sites may reflect a lack of consistency of the technical approaches and poor computational methods. This requires a critical next phase to first determine $m^{5} \mathrm{C}$ sites whose detection is robust to technical variation and computational analysis. Second, to increase the number of systemwide $\mathrm{m}^{5} \mathrm{C}$ detection studies before urging any conclusion on the specificity and regulation of the precise dynamics of this modification in vivo.

Novel approaches are still needed to overcome some of these issues. For instance, the combination of NGS techniques with well-defined and widely used techniques such as mass spectrometry could bring a broad new vision of the whole epitranscriptome. In this regard, 
advances have been made based on NAIL-MS (nucleic acid isotope labelling coupled mass spectrometry), which relies on the quantification of RNA modifications using stable isotopelabelled internal standards (SILIS) [104]. The adaptation of the nascent single-molecule, real-time (SMRT) sequencing technology for the detection of RNA sequences [105], may contribute to resolve site distribution maps in low abundance RNAs. Moreover, development of robust data analysis tools will be required to improve calling of $\mathrm{m}^{5} \mathrm{C}$ sites and elimination of stochastic artefacts.

While we are beginning to understand the molecular function of $m^{5} \mathrm{C}$ on non-coding RNAs, the molecular role of $\mathrm{m}^{5} \mathrm{C}$ occurrence in $\mathrm{mRNA}$ metabolism and the biological relevance of such a low prevalence mark still remains elusive. A unifying theme among most of the cytosine- 5 methyltransferase's roles is that they are linked to stress responses, development and cell differentiation. Yet, the functional roles of several RNA cytosine-5 methyltransferases remain to be established, and novel genetically modified cells and organism models are needed. Furthermore, the level of protein redundancy in RNA methylation pathways is unknown and depletion of individual RNA methyltransferases may not be sufficient to comprehensively understand their roles.

Expression alterations or mutations of $\mathrm{m}^{5} \mathrm{C}$ methyltransferases have been linked to several diseases, indicating an essential role in human physiology. Further identification of $\mathrm{m}^{5} \mathrm{C}$ and $\mathrm{hm}^{5} \mathrm{C}$ dynamic changes as well as their context-specific writers, erasers and protein readers are now the priority, that will shed light into the wide range of cellular processes being regulated by this epitranscriptomic marks. However, the main effort should be made in the characterization of the role of $\mathrm{m}^{5} \mathrm{C}$ in disease, leading to the search of molecules to rewire $\mathrm{m}^{5} \mathrm{C}$ deposition. Recent studies have indicated an association between alterations on $\mathrm{m}^{5} \mathrm{C}$ deposition and cancer, suggesting the targeting of RNA methyltransferases activity as a promising strategy to treat cancer [47]. The recent findings that TET and ALKBH1 have also the ability to oxidize $\mathrm{m}^{5} \mathrm{C}$ in RNA raise the question as to whether defects of $\mathrm{m}^{5} \mathrm{C}$ oxidative derivatives on RNA can lead to human diseases. Mutations in TET2 are associated to leukaemia and myeloid malignancies [106]. In addition, $A L K B H 1$ loci is susceptible to B-cell acute lymphoblastic leukaemia in children [107]. Mechanistically, the cause has been always associated to DNA demethylation defects. However, RNA hydroxymethylation defects could be also linked to TET and ALKBH1 associated diseases. Future findings of the potential of $\mathrm{m}^{5} \mathrm{C}$-modified RNA as diagnostic tool or RNA-modifying proteins as therapeutic targets to treat complex diseases including cancer and neurological diseases will be extremely interesting. 


\section{Acknowledgements}

R.G-V is a PhD student supported by a Spanish Ministry of Economy and Innovation (MINECO) PhD fellowship (BES-2017-080530). A. S. is a recipient of a Ramón y Cajal contract (RYC-2016-19962). S.B. is a Research Scientist (Científico Titular) of the Spanish Council Research (CSIC) and has been supported by a Ramón y Cajal fellowship for junior investigators (RYC-2014-16550). We acknowledge funding from the Spanish Ministry of Economy and Innovation (MINECO) and Agencia Estatal de Investigación (AEI) and cofinanced by the European Development Regional Fund (FEDER) under grant no. SAF201678667-R. We thank MINECO for the Ochoa Excellence Accreditation of CIC bioGUNE (SEV2016-0644). We gratefully thank Peter Humphreys for his editorial contribution. S.B.'s institution is supported by the Programa de Apoyo a Planes Estratégicos de Investigación de Estructuras de Investigación de Excelencia cofunded by the Castilla-León autonomous government and the European Regional Development Fund (CLC-2017-01). 


\section{References}

[1] P. Boccaletto, M.A. Machnicka, E. Purta, P. Piatkowski, B. Baginski, T.K. Wirecki, V. de Crecy-Lagard, R. Ross, P.A. Limbach, A. Kotter, M. Helm, J.M. Bujnicki, MODOMICS: a database of RNA modification pathways. 2017 update, Nucleic acids research, 46 (2018) D303-D307.

[2] D.T. Dubin, R.H. Taylor, The methylation state of poly A-containing messenger RNA from cultured hamster cells, Nucleic acids research, 2 (1975) 1653-1668.

[3] Y. Iwanami, G.M. Brown, Methylated bases of ribosomal ribonucleic acid from HeLa cells, Archives of biochemistry and biophysics, 126 (1968) 8-15.

[4] H.A. Raue, J. Klootwijk, W. Musters, Evolutionary conservation of structure and function of high molecular weight ribosomal RNA, Prog Biophys Mol Biol, 51 (1988) 77-129.

[5] D.T. Dubin, V. Stollar, Methylation of Sindbis virus "26S" messenger RNA, Biochemical and biophysical research communications, 66 (1975) 1373-1379.

[6] R. Desrosiers, K. Friderici, F. Rottman, Identification of methylated nucleosides in messenger RNA from Novikoff hepatoma cells, Proceedings of the National Academy of Sciences of the United States of America, 71 (1974) 3971-3975.

[7] T. Amort, D. Rieder, A. Wille, D. Khokhlova-Cubberley, C. Riml, L. Trixl, X.Y. Jia, R. Micura, A. Lusser, Distinct 5-methylcytosine profiles in poly(A) RNA from mouse embryonic stem cells and brain, Genome biology, 18 (2017) 1.

[8] S. Blanco, S. Dietmann, J.V. Flores, S. Hussain, C. Kutter, P. Humphreys, M. Lukk, P. Lombard, L. Treps, M. Popis, S. Kellner, S.M. Holter, L. Garrett, W. Wurst, L. Becker, T. Klopstock, H. Fuchs, V. Gailus-Durner, M. Hrabe de Angelis, R.T. Karadottir, M. Helm, J. Ule, J.G. Gleeson, D.T. Odom, M. Frye, Aberrant methylation of tRNAs links cellular stress to neuro-developmental disorders, The EMBO journal, 33 (2014) 2020-2039.

[9] X. Cui, Z. Liang, L. Shen, Q. Zhang, S. Bao, Y. Geng, B. Zhang, V. Leo, L.A. Vardy, T. Lu, X. Gu, H. Yu, 5-Methylcytosine RNA Methylation in Arabidopsis Thaliana, Mol Plant, 10 (2017) 1387-1399.

[10] S. Edelheit, S. Schwartz, M.R. Mumbach, O. Wurtzel, R. Sorek, Transcriptome-wide mapping of 5-methylcytidine RNA modifications in bacteria, archaea, and yeast reveals $\mathrm{m} 5 \mathrm{C}$ within archaeal mRNAs, PLoS genetics, 9 (2013) e1003602.

[11] J.E. Squires, H.R. Patel, M. Nousch, T. Sibbritt, D.T. Humphreys, B.J. Parker, C.M. Suter, T. Preiss, Widespread occurrence of 5-methylcytosine in human coding and non-coding RNA, Nucleic acids research, 40 (2012) 5023-5033.

[12] X. Yang, Y. Yang, B.F. Sun, Y.S. Chen, J.W. Xu, W.Y. Lai, A. Li, X. Wang, D.P. Bhattarai, W. Xiao, H.Y. Sun, Q. Zhu, H.L. Ma, S. Adhikari, M. Sun, Y.J. Hao, B. Zhang, C.M. Huang, N. Huang, G.B. Jiang, Y.L. Zhao, H.L. Wang, Y.P. Sun, Y.G. Yang, 5-methylcytosine promotes mRNA export - NSUN2 as the methyltransferase and ALYREF as an $\mathrm{m}(5) \mathrm{C}$ reader, Cell research, 27 (2017) 606-625.

[13] M. Schaefer, T. Pollex, K. Hanna, F. Tuorto, M. Meusburger, M. Helm, F. Lyko, RNA methylation by Dnmt2 protects transfer RNAs against stress-induced cleavage, Genes \& development, 24 (2010) 1590-1595.

[14] M. Schaefer, T. Pollex, K. Hanna, F. Lyko, RNA cytosine methylation analysis by bisulfite sequencing, Nucleic acids research, 37 (2009) e12. 
[15] V. Khoddami, B.R. Cairns, Identification of direct targets and modified bases of RNA cytosine methyltransferases, Nature biotechnology, 31 (2013) 458-464.

[16] S. Hussain, A.A. Sajini, S. Blanco, S. Dietmann, P. Lombard, Y. Sugimoto, M. Paramor, J.G. Gleeson, D.T. Odom, J. Ule, M. Frye, NSun2-mediated cytosine-5 methylation of vault noncoding RNA determines its processing into regulatory small RNAs, Cell reports, 4 (2013) 255-261.

[17] Y. Motorin, F. Lyko, M. Helm, 5-methylcytosine in RNA: detection, enzymatic formation and biological functions, Nucleic acids research, 38 (2010) 1415-1430.

[18] M. Frommer, L.E. McDonald, D.S. Millar, C.M. Collis, F. Watt, G.W. Grigg, P.L. Molloy, C.L. Paul, A genomic sequencing protocol that yields a positive display of 5-methylcytosine residues in individual DNA strands, Proceedings of the National Academy of Sciences of the United States of America, 89 (1992) 1827-1831.

[19] W. Gu, R.L. Hurto, A.K. Hopper, E.J. Grayhack, E.M. Phizicky, Depletion of Saccharomyces cerevisiae tRNA(His) guanylyltransferase Thg1p leads to uncharged tRNAHis with additional $\mathrm{m}(5) \mathrm{C}$, Molecular and cellular biology, 25 (2005) 8191-8201.

[20] R. David, A. Burgess, B. Parker, J. Li, K. Pulsford, T. Sibbritt, T. Preiss, I.R. Searle, Transcriptome-Wide Mapping of RNA 5-Methylcytosine in Arabidopsis mRNAs and Noncoding RNAs, The Plant cell, 29 (2017) 445-460.

[21] L. Van Haute, S. Dietmann, L. Kremer, S. Hussain, S.F. Pearce, C.A. Powell, J. Rorbach, R. Lantaff, S. Blanco, S. Sauer, U. Kotzaeridou, G.F. Hoffmann, Y. Memari, A. Kolb-Kokocinski, R. Durbin, J.A. Mayr, M. Frye, H. Prokisch, M. Minczuk, Deficient methylation and formylation of mt-tRNA(Met) wobble cytosine in a patient carrying mutations in NSUN3, Nature communications, 7 (2016) 12039.

[22] I. Behm-Ansmant, M. Helm, Y. Motorin, Use of specific chemical reagents for detection of modified nucleotides in RNA, J Nucleic Acids, 2011 (2011) 408053.

[23] V. Khoddami, A. Yerra, B.R. Cairns, Experimental Approaches for Target Profiling of RNA Cytosine Methyltransferases, Methods Enzymol, 560 (2015) 273-296.

[24] C. Legrand, F. Tuorto, M. Hartmann, R. Liebers, D. Jacob, M. Helm, F. Lyko, Statistically robust methylation calling for whole-transcriptome bisulfite sequencing reveals distinct methylation patterns for mouse RNAs, Genome Res, 27 (2017) 1589-1596.

[25] A.V. Grozhik, B. Linder, A.O. Olarerin-George, S.R. Jaffrey, Mapping m(6)A at IndividualNucleotide Resolution Using Crosslinking and Immunoprecipitation (miCLIP), Methods Mol Biol, 1562 (2017) 55-78.

[26] M.Y. King, K.L. Redman, RNA methyltransferases utilize two cysteine residues in the formation of 5-methylcytosine, Biochemistry, 41 (2002) 11218-11225.

[27] G. Bourgeois, M. Ney, I. Gaspar, C. Aigueperse, M. Schaefer, S. Kellner, M. Helm, Y. Motorin, Eukaryotic rRNA Modification by Yeast 5-Methylcytosine-Methyltransferases and Human Proliferation-Associated Antigen p120, PloS one, 10 (2015) e0133321.

[28] Y. Motorin, H. Grosjean, Multisite-specific tRNA:m5C-methyltransferase (Trm4) in yeast Saccharomyces cerevisiae: identification of the gene and substrate specificity of the enzyme, Rna, 5 (1999) 1105-1118.

[29] J.M. Bujnicki, M. Feder, C.L. Ayres, K.L. Redman, Sequence-structure-function studies of tRNA:m5C methyltransferase Trm4p and its relationship to DNA:m5C and RNA:m5U methyltransferases, Nucleic acids research, 32 (2004) 2453-2463.

[30] C.T. Chan, Y.L. Pang, W. Deng, I.R. Babu, M. Dyavaiah, T.J. Begley, P.C. Dedon, Reprogramming of tRNA modifications controls the oxidative stress response by codonbiased translation of proteins, Nature communications, 3 (2012) 937. 
[31] A.L. Burgess, R. David, I.R. Searle, Conservation of tRNA and rRNA 5-methylcytosine in the kingdom Plantae, BMC plant biology, 15 (2015) 199.

[32] M.G. Goll, F. Kirpekar, K.A. Maggert, J.A. Yoder, C.L. Hsieh, X. Zhang, K.G. Golic, S.E. Jacobsen, T.H. Bestor, Methylation of tRNAAsp by the DNA methyltransferase homolog Dnmt2, Science, 311 (2006) 395-398.

[33] F. Tuorto, F. Herbst, N. Alerasool, S. Bender, O. Popp, G. Federico, S. Reitter, R. Liebers, G. Stoecklin, H.J. Grone, G. Dittmar, H. Glimm, F. Lyko, The tRNA methyltransferase Dnmt2 is required for accurate polypeptide synthesis during haematopoiesis, The EMBO journal, (2015).

[34] S. Haag, K.E. Sloan, N. Ranjan, A.S. Warda, J. Kretschmer, C. Blessing, B. Hubner, J. Seikowski, S. Dennerlein, P. Rehling, M.V. Rodnina, C. Hobartner, M.T. Bohnsack, NSUN3 and $\mathrm{ABH} 1$ modify the wobble position of mt-tRNAMet to expand codon recognition in mitochondrial translation, The EMBO journal, 35 (2016) 2104-2119.

[35] S. Haag, A.S. Warda, J. Kretschmer, M.A. Gunnigmann, C. Hobartner, M.T. Bohnsack, NSUN6 is a human RNA methyltransferase that catalyzes formation of $\mathrm{m} 5 \mathrm{C} 72$ in specific tRNAs, Rna, 21 (2015) 1532-1543.

[36] S. Nakano, T. Suzuki, L. Kawarada, H. Iwata, K. Asano, T. Suzuki, NSUN3 methylase initiates 5-formylcytidine biogenesis in human mitochondrial tRNA(Met), Nature chemical biology, 12 (2016) 546-551.

[37] F. Tuorto, R. Liebers, T. Musch, M. Schaefer, S. Hofmann, S. Kellner, M. Frye, M. Helm, G. Stoecklin, F. Lyko, RNA cytosine methylation by Dnmt2 and NSun2 promotes tRNA stability and protein synthesis, Nature structural \& molecular biology, 19 (2012) 900-905.

[38] Z. Durdevic, K. Hanna, B. Gold, T. Pollex, S. Cherry, F. Lyko, M. Schaefer, Efficient RNA virus control in Drosophila requires the RNA methyltransferase Dnmt2, EMBO Rep, 14 (2013) 269-275.

[39] Z. Durdevic, M.B. Mobin, K. Hanna, F. Lyko, M. Schaefer, The RNA methyltransferase Dnmt2 is required for efficient Dicer-2-dependent siRNA pathway activity in Drosophila, Cell reports, 4 (2013) 931-937.

[40] K. Rai, S. Chidester, C.V. Zavala, E.J. Manos, S.R. James, A.R. Karpf, D.A. Jones, B.R. Cairns, Dnmt2 functions in the cytoplasm to promote liver, brain, and retina development in zebrafish, Genes \& development, 21 (2007) 261-266.

[41] R. Shanmugam, J. Fierer, S. Kaiser, M. Helm, T.P. Jurkowski, A. Jeltsch, Cytosine methylation of tRNA-Asp by DNMT2 has a role in translation of proteins containing poly-Asp sequences, Cell Discov, 1 (2015) 15010.

[42] Y. Zhang, X. Zhang, J. Shi, F. Tuorto, X. Li, Y. Liu, R. Liebers, L. Zhang, Y. Qu, J. Qian, M. Pahima, Y. Liu, M. Yan, Z. Cao, X. Lei, Y. Cao, H. Peng, S. Liu, Y. Wang, H. Zheng, R. Woolsey, D. Quilici, Q. Zhai, L. Li, T. Zhou, W. Yan, F. Lyko, Y. Zhang, Q. Zhou, E. Duan, Q. Chen, Dnmt2 mediates intergenerational transmission of paternally acquired metabolic disorders through sperm small non-coding RNAs, Nature cell biology, 20 (2018) 535-540.

[43] S. Blanco, A. Kurowski, J. Nichols, F.M. Watt, S.A. Benitah, M. Frye, The RNAmethyltransferase Misu (NSun2) poises epidermal stem cells to differentiate, PLoS genetics, 7 (2011) e1002403.

[44] M. Frye, I. Dragoni, S.F. Chin, I. Spiteri, A. Kurowski, E. Provenzano, A. Green, I.O. Ellis, D. Grimmer, A. Teschendorff, C.C. Zouboulis, C. Caldas, F.M. Watt, Genomic gain of 5p15 leads to over-expression of Misu (NSUN2) in breast cancer, Cancer letters, 289 (2010) 71-80. 
[45] S. Hussain, S.B. Benavente, E. Nascimento, I. Dragoni, A. Kurowski, A. Gillich, P. Humphreys, M. Frye, The nucleolar RNA methyltransferase Misu (NSun2) is required for mitotic spindle stability, The Journal of cell biology, 186 (2009) 27-40.

[46] S. Hussain, F. Tuorto, S. Menon, S. Blanco, C. Cox, J.V. Flores, S. Watt, N.R. Kudo, F. Lyko, M. Frye, The mouse cytosine-5 RNA methyltransferase NSun2 is a component of the chromatoid body and required for testis differentiation, Molecular and cellular biology, 33 (2013) 1561-1570.

[47] S. Blanco, R. Bandiera, M. Popis, S. Hussain, P. Lombard, J. Aleksic, A. Sajini, H. Tanna, R. Cortes-Garrido, N. Gkatza, S. Dietmann, M. Frye, Stem cell function and stress response are controlled by protein synthesis, Nature, 534 (2016) 335-340.

[48] J.V. Flores, L. Cordero-Espinoza, F. Oeztuerk-Winder, A. Andersson-Rolf, T. Selmi, S. Blanco, J. Tailor, S. Dietmann, M. Frye, Cytosine-5 RNA Methylation Regulates Neural Stem Cell Differentiation and Motility, Stem Cell Reports, 8 (2017) 112-124.

[49] S. Muller, I.M. Windhof, V. Maximov, T. Jurkowski, A. Jeltsch, K.U. Forstner, C.M. Sharma, R. Graf, W. Nellen, Target recognition, RNA methylation activity and transcriptional regulation of the Dictyostelium discoideum Dnmt2-homologue (DnmA), Nucleic acids research, 41 (2013) 8615-8627.

[50] M. Becker, S. Muller, W. Nellen, T.P. Jurkowski, A. Jeltsch, A.E. Ehrenhofer-Murray, Pmt1, a Dnmt2 homolog in Schizosaccharomyces pombe, mediates tRNA methylation in response to nutrient signaling, Nucleic acids research, 40 (2012) 11648-11658.

[51] S.K. Natchiar, A.G. Myasnikov, H. Kratzat, I. Hazemann, B.P. Klaholz, Visualization of chemical modifications in the human 80S ribosome structure, Nature, 551 (2017) 472-477.

[52] S. Sharma, J. Yang, P. Watzinger, P. Kotter, K.D. Entian, Yeast Nop2 and Rcm1 methylate C2870 and C2278 of the 25S rRNA, respectively, Nucleic acids research, 41 (2013) 90629076.

[53] M.D. Metodiev, H. Spahr, P. Loguercio Polosa, C. Meharg, C. Becker, J. Altmueller, B. Habermann, N.G. Larsson, B. Ruzzenente, NSUN4 is a dual function mitochondrial protein required for both methylation of $12 \mathrm{~S}$ rRNA and coordination of mitoribosomal assembly, PLoS genetics, 10 (2014) e1004110.

[54] R.P. Perry, D.E. Kelley, K. Friderici, F. Rottman, The methylated constituents of L cell messenger RNA: evidence for an unusual cluster at the 5 ' terminus, Cell, 4 (1975) 387-394.

[55] L. Fu, C.R. Guerrero, N. Zhong, N.J. Amato, Y. Liu, S. Liu, Q. Cai, D. Ji, S.G. Jin, L.J. Niedernhofer, G.P. Pfeifer, G.L. Xu, Y. Wang, Tet-mediated formation of 5hydroxymethylcytosine in RNA, Journal of the American Chemical Society, 136 (2014) $11582-11585$.

[56] W. Huang, M.D. Lan, C.B. Qi, S.J. Zheng, S.Z. Wei, B.F. Yuan, Y.Q. Feng, Formation and determination of the oxidation products of 5-methylcytosine in RNA, Chem Sci, 7 (2016) 5495-5502.

[57] S.M. Huber, P. van Delft, L. Mendil, M. Bachman, K. Smollett, F. Werner, E.A. Miska, S. Balasubramanian, Formation and abundance of 5-hydroxymethylcytosine in RNA, Chembiochem : a European journal of chemical biology, 16 (2015) 752-755.

[58] T. Amort, M.F. Souliere, A. Wille, X.Y. Jia, H. Fiegl, H. Worle, R. Micura, A. Lusser, Long non-coding RNAs as targets for cytosine methylation, RNA biology, 10 (2013) 1003-1008.

[59] F. Aguilo, S. Li, N. Balasubramaniyan, A. Sancho, S. Benko, F. Zhang, A. Vashisht, M. Rengasamy, B. Andino, C.H. Chen, F. Zhou, C. Qian, M.M. Zhou, J.A. Wohlschlegel, W. Zhang, F.J. Suchy, M.J. Walsh, Deposition of 5-Methylcytosine on Enhancer RNAs Enables the Coactivator Function of PGC-1alpha, Cell reports, 14 (2016) 479-492. 
[60] A. Alexandrov, I. Chernyakov, W. Gu, S.L. Hiley, T.R. Hughes, E.J. Grayhack, E.M. Phizicky, Rapid tRNA decay can result from lack of nonessential modifications, Molecular cell, 21 (2006) 87-96.

[61] I. Chernyakov, J.M. Whipple, L. Kotelawala, E.J. Grayhack, E.M. Phizicky, Degradation of several hypomodified mature tRNA species in Saccharomyces cerevisiae is mediated by Met22 and the 5'-3' exonucleases Rat1 and Xrn1, Genes \& development, 22 (2008) 13691380.

[62] M.C. Strobel, J. Abelson, Effect of intron mutations on processing and function of Saccharomyces cerevisiae SUP53 tRNA in vitro and in vivo, Molecular and cellular biology, 6 (1986) 2663-2673.

[63] P. Wu, J.S. Brockenbrough, M.R. Paddy, J.P. Aris, NCL1, a novel gene for a non-essential nuclear protein in Saccharomyces cerevisiae, Gene, 220 (1998) 109-117.

[64] M. Frye, F.M. Watt, The RNA methyltransferase Misu (NSun2) mediates Myc-induced proliferation and is upregulated in tumors, Current biology : CB, 16 (2006) 971-981.

[65] L. Chi, P. Delgado-Olguin, Expression of NOL1/NOP2/sun domain (Nsun) RNA methyltransferase family genes in early mouse embryogenesis, Gene expression patterns : GEP, 13 (2013) 319-327.

[66] L. Kawarada, T. Suzuki, T. Ohira, S. Hirata, K. Miyauchi, T. Suzuki, ALKBH1 is an RNA dioxygenase responsible for cytoplasmic and mitochondrial tRNA modifications, Nucleic acids research, 45 (2017) 7401-7415.

[67] L. Trixl, T. Amort, A. Wille, M. Zinni, S. Ebner, C. Hechenberger, F. Eichin, H. Gabriel, I. Schoberleitner, A. Huang, P. Piatti, R. Nat, J. Troppmair, A. Lusser, RNA cytosine methyltransferase Nsun3 regulates embryonic stem cell differentiation by promoting mitochondrial activity, Cellular and molecular life sciences : CMLS, 75 (2018) 1483-1497.

[68] L. Tafforeau, C. Zorbas, J.L. Langhendries, S.T. Mullineux, V. Stamatopoulou, R. Mullier, L. Wacheul, D.L. Lafontaine, The complexity of human ribosome biogenesis revealed by systematic nucleolar screening of Pre-rRNA processing factors, Molecular cell, 51 (2013) 539-551.

[69] B. Hong, J.S. Brockenbrough, P. Wu, J.P. Aris, Nop2p is required for pre-rRNA processing and 60S ribosome subunit synthesis in yeast, Molecular and cellular biology, 17 (1997) 378388.

[70] M. Schosserer, N. Minois, T.B. Angerer, M. Amring, H. Dellago, E. Harreither, A. CallePerez, A. Pircher, M.P. Gerstl, S. Pfeifenberger, C. Brandl, M. Sonntagbauer, A. Kriegner, A. Linder, A. Weinhausel, T. Mohr, M. Steiger, D. Mattanovich, M. Rinnerthaler, T. Karl, S. Sharma, K.D. Entian, M. Kos, M. Breitenbach, I.B. Wilson, N. Polacek, R. Grillari-Voglauer, L. Breitenbach-Koller, J. Grillari, Methylation of ribosomal RNA by NSUN5 is a conserved mechanism modulating organismal lifespan, Nature communications, 6 (2015) 6158.

[71] N. Krogh, M.D. Jansson, S.J. Hafner, D. Tehler, U. Birkedal, M. Christensen-Dalsgaard, A.H. Lund, H. Nielsen, Profiling of 2'-O-Me in human rRNA reveals a subset of fractionally modified positions and provides evidence for ribosome heterogeneity, Nucleic acids research, 44 (2016) 7884-7895.

[72] A. Basu, P. Das, S. Chaudhuri, E. Bevilacqua, J. Andrews, S. Barik, M. Hatzoglou, A.A. Komar, B. Mazumder, Requirement of rRNA methylation for $80 \mathrm{~S}$ ribosome assembly on a cohort of cellular internal ribosome entry sites, Molecular and cellular biology, 31 (2011) 4482-4499. 
[73] L. Perlaky, B.C. Valdez, R.K. Busch, R.G. Larson, S.M. Jhiang, W.W. Zhang, M. Brattain, H. Busch, Increased growth of NIH/3T3 cells by transfection with human p120 complementary DNA and inhibition by a p120 antisense construct, Cancer research, 52 (1992) 428-436.

[74] T. Harris, B. Marquez, S. Suarez, J. Schimenti, Sperm motility defects and infertility in male mice with a mutation in Nsun7, a member of the Sun domain-containing family of putative RNA methyltransferases, Biology of reproduction, 77 (2007) 376-382.

[75] B. Genenncher, Z. Durdevic, K. Hanna, D. Zinkl, M.B. Mobin, N. Senturk, B. Da Silva, C. Legrand, C. Carre, F. Lyko, M. Schaefer, Mutations in Cytosine-5 tRNA Methyltransferases Impact Mobile Element Expression and Genome Stability at Specific DNA Repeats, Cell reports, 22 (2018) 1861-1874.

[76] H. Ghanbarian, N. Wagner, B. Polo, D. Baudouy, J. Kiani, J.F. Michiels, F. Cuzin, M. Rassoulzadegan, K.D. Wagner, Dnmt2/Trdmt1 as Mediator of RNA Polymerase II Transcriptional Activity in Cardiac Growth, PloS one, 11 (2016) e0156953.

[77] D. Haussecker, Y. Huang, A. Lau, P. Parameswaran, A.Z. Fire, M.A. Kay, Human tRNAderived small RNAs in the global regulation of RNA silencing, Rna, 16 (2010) 673-695.

[78] T.P. Hoernes, N. Clementi, K. Faserl, H. Glasner, K. Breuker, H. Lindner, A. Huttenhofer, M.D. Erlacher, Nucleotide modifications within bacterial messenger RNAs regulate their translation and are able to rewire the genetic code, Nucleic acids research, 44 (2016) 852862.

[79] H. Tang, X. Fan, J. Xing, Z. Liu, B. Jiang, Y. Dou, M. Gorospe, W. Wang, NSun2 delays replicative senescence by repressing p27 (KIP1) translation and elevating CDK1 translation, Aging, 7 (2015) 1143-1158.

[80] N. Wang, H. Tang, X. Wang, W. Wang, J. Feng, Homocysteine upregulates interleukin17A expression via NSun2-mediated RNA methylation in T lymphocytes, Biochemical and biophysical research communications, 493 (2017) 94-99.

[81] J. Xing, J. Yi, X. Cai, H. Tang, Z. Liu, X. Zhang, J.L. Martindale, X. Yang, B. Jiang, M. Gorospe, W. Wang, NSun2 Promotes Cell Growth via Elevating Cyclin-Dependent Kinase 1 Translation, Molecular and cellular biology, 35 (2015) 4043-4052.

[82] Q. Shen, Q. Zhang, Y. Shi, Q. Shi, Y. Jiang, Y. Gu, Z. Li, X. Li, K. Zhao, C. Wang, N. Li, X. Cao, Tet2 promotes pathogen infection-induced myelopoiesis through mRNA oxidation, Nature, 554 (2018) 123-127.

[83] Y. Huang, G. Wang, Z. Liang, Y. Yang, L. Cui, C.Y. Liu, Loss of nuclear localization of TET2 in colorectal cancer, Clin Epigenetics, 8 (2016) 9.

[84] Z. Miao, N. Xin, B. Wei, X. Hua, G. Zhang, C. Leng, C. Zhao, D. Wu, J. Li, W. Ge, M. Sun, X. $\mathrm{Xu}, 5$-hydroxymethylcytosine is detected in RNA from mouse brain tissues, Brain Res, 1642 (2016) 546-552.

[85] H. Lian, W.B. Li, W.L. Jin, The emerging insights into catalytic or non-catalytic roles of TET proteins in tumors and neural development, Oncotarget, 7 (2016) 64512-64525.

[86] D. Guallar, X. Bi, J.A. Pardavila, X. Huang, C. Saenz, X. Shi, H. Zhou, F. Faiola, J. Ding, P. Haruehanroengra, F. Yang, D. Li, C. Sanchez-Priego, A. Saunders, F. Pan, V.J. Valdes, K. Kelley, M.G. Blanco, L. Chen, H. Wang, J. Sheng, M. Xu, M. Fidalgo, X. Shen, J. Wang, RNAdependent chromatin targeting of TET2 for endogenous retrovirus control in pluripotent stem cells, Nature genetics, 50 (2018) 443-451.

[87] M. Basanta-Sanchez, R. Wang, Z. Liu, X. Ye, M. Li, X. Shi, P.F. Agris, Y. Zhou, Y. Huang, J. Sheng, TET1-Mediated Oxidation of 5-Formylcytosine $(5 \mathrm{fC})$ to 5-Carboxycytosine $(5 \mathrm{caC})$ in RNA, Chembiochem, 18 (2017) 72-76. 
[88] S.M. Jhiang, M. Yaneva, H. Busch, Expression of human proliferation-associated nucleolar antigen p120, Cell Growth Differ, 1 (1990) 319-324.

[89] J.W. Freeman, P. McGrath, V. Bondada, N. Selliah, H. Ownby, T. Maloney, R.K. Busch, H. Busch, Prognostic significance of proliferation associated nucleolar antigen P120 in human breast carcinoma, Cancer research, 51 (1991) 1973-1978.

[90] J.C. Yang, E. Risch, M. Zhang, C. Huang, H. Huang, L. Lu, Association of tRNA methyltransferase NSUN2/IGF-II molecular signature with ovarian cancer survival, Future Oncol, 13 (2017) 1981-1990.

[91] Y. Li, J. Li, M. Luo, C. Zhou, X. Shi, W. Yang, Z. Lu, Z. Chen, N. Sun, J. He, Novel long noncoding RNA NMR promotes tumor progression via NSUN2 and BPTF in esophageal squamous cell carcinoma, Cancer letters, 430 (2018) 57-66.

[92] L. Lu, G. Zhu, H. Zeng, Q. Xu, K. Holzmann, High tRNA Transferase NSUN2 Gene Expression is Associated with Poor Prognosis in Head and Neck Squamous Carcinoma, Cancer Invest, 36 (2018) 246-253.

[93] M.A. Khan, M.A. Rafiq, A. Noor, S. Hussain, J.V. Flores, V. Rupp, A.K. Vincent, R. Malli, G. Ali, F.S. Khan, G.E. Ishak, D. Doherty, R. Weksberg, M. Ayub, C. Windpassinger, S. Ibrahim, M. Frye, M. Ansar, J.B. Vincent, Mutation in NSUN2, which encodes an RNA methyltransferase, causes autosomal-recessive intellectual disability, American journal of human genetics, 90 (2012) 856-863.

[94] F.J. Martinez, J.H. Lee, J.E. Lee, S. Blanco, E. Nickerson, S. Gabriel, M. Frye, L. Al-Gazali, J.G. Gleeson, Whole exome sequencing identifies a splicing mutation in NSUN2 as a cause of a Dubowitz-like syndrome, Journal of medical genetics, 49 (2012) 380-385.

[95] L. Abbasi-Moheb, S. Mertel, M. Gonsior, L. Nouri-Vahid, K. Kahrizi, S. Cirak, D. Wieczorek, M.M. Motazacker, S. Esmaeeli-Nieh, K. Cremer, R. Weissmann, A. Tzschach, M. Garshasbi, S.S. Abedini, H. Najmabadi, H.H. Ropers, S.J. Sigrist, A.W. Kuss, Mutations in NSUN2 cause autosomal-recessive intellectual disability, American journal of human genetics, 90 (2012) 847-855.

[96] S. Ghadami, H.M. Mohammadi, J. Malbin, M. Masoodifard, A.B. Sarhaddi, J. TavakkolyBazzaz, S. Zeinali, Frequencies of Six (Five Novel) STR Markers Linked to TUSC3 (MRT7) or NSUN2 (MRT5) Genes Used for Homozygosity Mapping of Recessive Intellectual Disability, Clinical laboratory, 61 (2015) 925-932.

[97] M. Komara, A.M. Al-Shamsi, S. Ben-Salem, B.R. Ali, L. Al-Gazali, A Novel SingleNucleotide Deletion (c.1020delA) in NSUN2 Causes Intellectual Disability in an Emirati Child, J Mol Neurosci, 57 (2015) 393-399.

[98] S. Fahiminiya, M. Almuriekhi, Z. Nawaz, A. Staffa, P. Lepage, R. Ali, L. Hashim, J. Schwartzentruber, K. Abu Khadija, S. Zaineddin, H. Gamal, J. Majewski, T. Ben-Omran, Whole exome sequencing unravels disease-causing genes in consanguineous families in Qatar, Clinical genetics, 86 (2014) 134-141.

[99] A. Doll, K.H. Grzeschik, Characterization of two novel genes, WBSCR20 and WBSCR22, deleted in Williams-Beuren syndrome, Cytogenetics and cell genetics, 95 (2001) 20-27.

[100] M.A. Martens, S.J. Wilson, D.C. Reutens, Research Review: Williams syndrome: a critical review of the cognitive, behavioral, and neuroanatomical phenotype, J Child Psychol Psychiatry, 49 (2008) 576-608.

[101] N. Khosronezhad, A. Hosseinzadeh Colagar, S.M. Mortazavi, The Nsun7 (A11337)deletion mutation, causes reduction of its protein rate and associated with sperm motility defect in infertile men, J Assist Reprod Genet, 32 (2015) 807-815. 
[102] N. Khosronezhad, A.H. Colagar, S.G. Jorsarayi, T26248G-transversion mutation in exon7 of the putative methyltransferase Nsun7 gene causes a change in protein folding associated with reduced sperm motility in asthenospermic men, Reproduction, fertility, and development, (2014).

[103] W. Elhardt, R. Shanmugam, T.P. Jurkowski, A. Jeltsch, Somatic cancer mutations in the DNMT2 tRNA methyltransferase alter its catalytic properties, Biochimie, 112 (2015) 66-72.

[104] M. Heiss, V.F. Reichle, S. Kellner, Observing the fate of tRNA and its modifications by nucleic acid isotope labeling mass spectrometry: NAIL-MS, in: RNA Biol, vol. 14, 2017, pp. 1260-1268.

[105] R.J. Roberts, M.O. Carneiro, M.C. Schatz, The advantages of SMRT sequencing, in: Genome Biol, vol. 14, England, 2013, pp. 405.

[106] S. Weissmann, T. Alpermann, V. Grossmann, A. Kowarsch, N. Nadarajah, C. Eder, F. Dicker, A. Fasan, C. Haferlach, T. Haferlach, W. Kern, S. Schnittger, A. Kohlmann, Landscape of TET2 mutations in acute myeloid leukemia, Leukemia, 26 (2012) 934-942.

[107] N.P. Archer, V. Perez-Andreu, M.E. Scheurer, K.R. Rabin, E.C. Peckham-Gregory, S.E. Plon, R.C. Zabriskie, P.A. De Alarcon, K.S. Fernandez, C.R. Najera, J.J. Yang, F. AntillonKlussmann, P.J. Lupo, Family-based exome-wide assessment of maternal genetic effects on susceptibility to childhood B-cell acute lymphoblastic leukemia in hispanics, Cancer, 122 (2016) 3697-3704. 
Table 1. Human Diseases associated to $m^{5} \mathrm{C}$ deposition alterations

\begin{tabular}{|c|c|c|c|c|}
\hline Factor & Role & Associated pathologies & Disease Area & References \\
\hline NOP2 & Writer & $\begin{array}{l}\text { Increased expression in several cancer } \\
\text { types }\end{array}$ & Cancer & $\begin{array}{l}\text { J.W. Freeman, P. McGrath, 1991; S.M. Jhiang, M. Yaneva, } \\
\text { 1990; T. Bocker, A. Bittinger, 1995; T. Ueki, Y. Nakayama, } \\
\text { 1997; Kuwano, M. Tsuneyoshi, 1997. }\end{array}$ \\
\hline NSUN2 & Writer & $\begin{array}{l}\text { Dubowitz-like syndrome and intellectual } \\
\text { disability }\end{array}$ & Neurological & $\begin{array}{l}\text { M.A. Khan, M.A. Rafiq, 2012; F.J. Martinez, J.H. Lee, 2012; } \\
\text { L. Abbasi-Moheb, S. Mertel, 2012; M. Komara, A.M. Al- } \\
\text { Shamsi, 2015; S. Ghadami, H.M. Mohammadi, } 2015 .\end{array}$ \\
\hline NSUN2 & Writer & Noonan-like syndrome & Cardiovascular & S. Fahiminiya, M. Almuriekhi, 2014. \\
\hline NSUN2 & Writer & $\begin{array}{l}\text { Altered expression of NSUN2 in several } \\
\text { cancer types }\end{array}$ & Cancer & $\begin{array}{l}\text { M. Frye, F.M. Watt, 2006; J.C. Yang, E. Risch, 2017; Y. Li, J. } \\
\text { Li, M. Luo, 2018, L. Lu, G. Zhu, } 2018 .\end{array}$ \\
\hline NSUN3 & Writer & $\begin{array}{l}\text { Mitochondrial respiratory chain complex } \\
\text { deficiency }\end{array}$ & Mitochondrial & $\begin{array}{l}\text { L. Van Haute, S. Dietmann, 2016; S. Nakano, T. Suzuki, } \\
2016 .\end{array}$ \\
\hline NSUN4 & Writer & $\begin{array}{l}\text { Loci susceptibility in breast, ovarian and } \\
\text { prostate cancer }\end{array}$ & Cancer & S.P. Kar, J. Beesley, 2016. \\
\hline NSUN5 & Writer & $\begin{array}{l}\text { Williams-Beuren syndrome } \\
\text { Neurodevelopmental disorder }\end{array}$ & Neurological & $\begin{array}{l}\text { A. Doll, K.H. Grzeschik, 2001; G. Merla, C. Ucla, 2002; M.A. } \\
\text { Martens, S.J. Wilson, } 2008 .\end{array}$ \\
\hline NSUN7 & Writer & Impaired sperm motility & Infertility & $\begin{array}{l}\text { N. Khosronezhad, A.H. Colagar, 2015; N. Khosronezhad, A. } \\
\text { Hosseinzadeh Colagar, 2015; H.Y. Ren, R. Zhong, 2015; } \\
\text { S.A. Forbes, D. Beare, 2015. }\end{array}$ \\
\hline DNMT2 & Writer & $\begin{array}{l}\text { Altered expression and mutations in } \\
\text { several cancer types }\end{array}$ & Cancer & $\begin{array}{l}\text { W. Elhardt, R. Shanmugam, 2015; S.A. Forbes, D. Beare, } \\
2015 .\end{array}$ \\
\hline TET1 & Eraser & Leukaemia & Cancer & R.B. Lorsbach, J. Moore, 2003. \\
\hline TET2 & Eraser & Myelodysplastic syndrome, Leukaemia & Cancer & $\begin{array}{l}\text { S. Weissmann, T. Alpermann, 2012; W.C. Chou, S.C. Chou, } \\
\text { 2011; B. Euba, J.L. Vizmanos, 2012; M. Ko, Y. Huang,, } \\
2010 .\end{array}$ \\
\hline ALYREF & Reader & $\begin{array}{l}\text { Altered expression in a variety of } \\
\text { tumours }\end{array}$ & Cancer & $\begin{array}{l}\text { Y. Saito, A. Kasamatsu, 2013; M.S. Dominguez-Sanchez, C. } \\
\text { Saez. } 2011 .\end{array}$ \\
\hline $\begin{array}{l}\text { Vault } \\
\text { RNA }\end{array}$ & Substrate & $\begin{array}{l}\text { Play a role in resistance development of } \\
\text { cancer cells to chemotherapeutic drugs }\end{array}$ & Cancer & $\begin{array}{l}\text { J. Chen, H. OuYang, 2018; S.C. Gopinath, R. Wadhwa, } \\
2010 .\end{array}$ \\
\hline ALKBH1 & Eraser & $\begin{array}{l}\text { Susceptibility to childhood B-cell acute } \\
\text { lymphoblastic leukaemia }\end{array}$ & Cancer & N.P. Archer, V. Perez-Andreu, 2016. \\
\hline
\end{tabular}




\section{Figure legends}

Figure 1. Schematic overview of RNA cytosine methylation detection techniques followed by next generation sequencing. Bisulphite sequencing (BS-Seq) relies on the differential reaction of cytosines to sodium bisulphite. $m^{5} \mathrm{C}$-RNA immunoprecipitation ( $\left.m^{5} \mathrm{C}-\mathrm{RIP}\right)$, 5azacitydine mediated RNA-IP and methylation-individual nucleotide resolution crosslinkingIP (mi-CLIP) are based on the use of antibodies that bind specifically to $\mathrm{m}^{5} \mathrm{C}$ marks or to the complex methyltransferase-RNA. Aza-IP and mi-CLIP provide information of methyltransferase particular substrates. In mi-CLIP, RNA-enzyme abducts are formed by using methyltransferase inactive mutants that bind covalently to the substrate. IP: immunoprecipitation.

Figure 2. $\mathrm{m}^{5} \mathrm{C}$ deposition landscape and cytosine-5 methyltransferases. Coding (mRNA) and non-coding RNAs are methylated at cytosine-C5 by the cytosine-5-methylases of the NOP2/Sun domain RNA methyltransferase family (NOP2, NSUN2-7 and TRM4B in higher eukaryotes, Trm4, Nop2 and Rcm1 in yeasts) and DNA methyltransferase family (DNMT2/TRDMT1 in higher eukaryotes, Pmt1 in yeast and DnmA in Dictyostelium). Methylated positions are indicated by coloured balloons, as well as the responsible enzymes. Star indicates protein interaction. Arrows indicate nuclear to cytosol export of methylated RNAs. tRNA: transfer RNA; pre-mRNA: pre-messenger RNA; eRNA: enhancer long non-coding RNA; rRNA: ribosomal RNA. ? indicates $m^{5} \mathrm{C}$ positions catalysed by an unknown RNA methylase.

Figure 3. Post-transcriptional expression regulation by cytosine-5 methylation of RNAs. A) NSUN2 methylation protects tRNAs from Angiogenin (ANG)-mediated cleavage into tRNA fragments (tRFs) that repressed translation. B) NSUN2 methylation protects Vault RNAs from cleavage into small RNAs that interact with the silencing machinery. C) Rcm1mediated methylation of $25 \mathrm{~S}$ rRNA at the large ribosomal subunit re-programmes the translation machinery. D) NSUN3-mediated methylation of mitochondrial tRNAs and NSUN4-mediated methylation of mitochondrial rRNAs enhances protein translation at the mitochondria. RISC: RNA-induced silencing complex. E) NSUN7 interacts with the transcriptional co-activator PGC-1a (Peroxisome proliferator-activated receptor-gamma coactivator 1 alpha) and promoter-derived eRNAs (enhancer RNAs) and reinforces transcription of PGC-1a-transcriptionally dependent genes. F) The lack of C38 tRNA methylation reduces the capacity of tRNAs to properly discriminate between Asp and Glu codons. 
Figure 4. Functional role of tRNA methyltransferases in Drosophila. A) Lack of Dnmt2 leads to increased tRNA fragmentation in stress conditions. The accumulation of tRFs inhibits Dicer-2 (DCR-2) complex activity, thereby decreasing the production of siRNA (small-interfering RNAs) and miRNAs (microRNAs) leading to inefficient silencing pathway activity. B) Upon infection of Drosophila C virus (DCV), Dnmt2, in wild-type (wt) flies, binds to viral RNAs (vRNA) leading to the neutralisation of the virus and anti-viral defence. Without Dnmt2 (Dnmt2-null flies), virus detection is inefficient leading to the virus to propagate. C) Lack of Dnmt2- and Nsun2-mediated methylation leads to silencing defects of transposable elements (TEs) in a heat-shock dependent and independent manner, respectively. tRFs: tRNA fragments; dsRNA: double-stranded RNA; ARGO: Argonaute.

Figure 5. $\mathrm{m}^{5} \mathrm{C}$ regulates $\mathrm{mRNA}$ export to the cytoplasm. NSUN2-methylated mRNAs are selectively transferred to the cytoplasm by the export factor AlyREF. SAM: S-AdenosylMethionine; SAH: S-Adenosyl-Homocysteine.

Figure 6. Enzymatic oxidation of 5-methylcytosine. 5-methylcytosine formation in RNA is catalysed by the NSUN family and DNMT2. 5-methylcytosine is oxidized to 5hydroxymethylcytosine by Ten-eleven Translocation (TET) enzymes in mRNA and by the Alkylation repair homologues family member ALKBH1 in tRNAs. 5-formylcytosine formation is catalysed ALKBH1. TET1 converts 5-formylcytosine to 5-carboycytosines.? indicates that it is yet unknown whether $\mathrm{m}^{5} \mathrm{C}$ can be completely removed. 
Figure 2

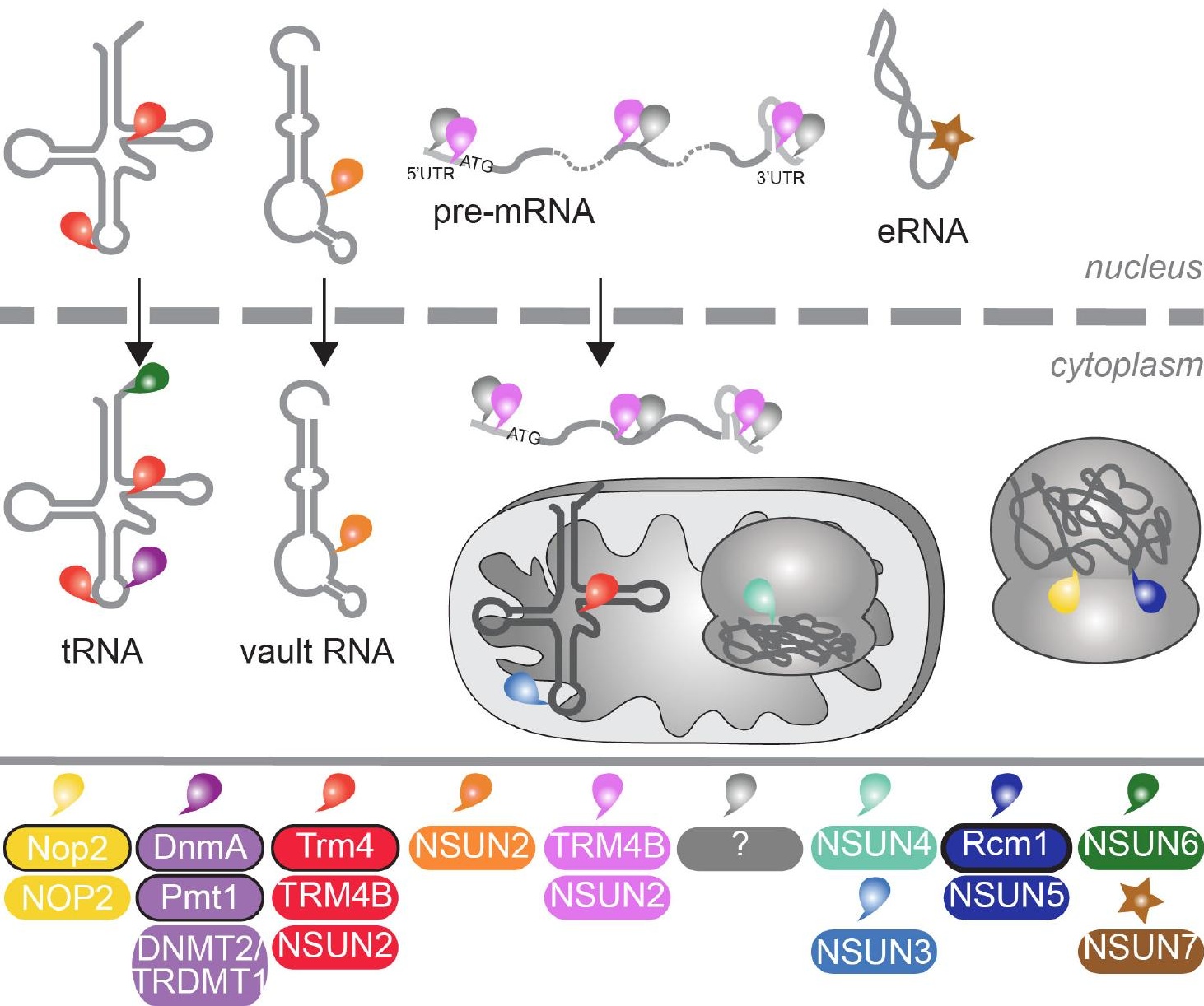


Figure 3

A

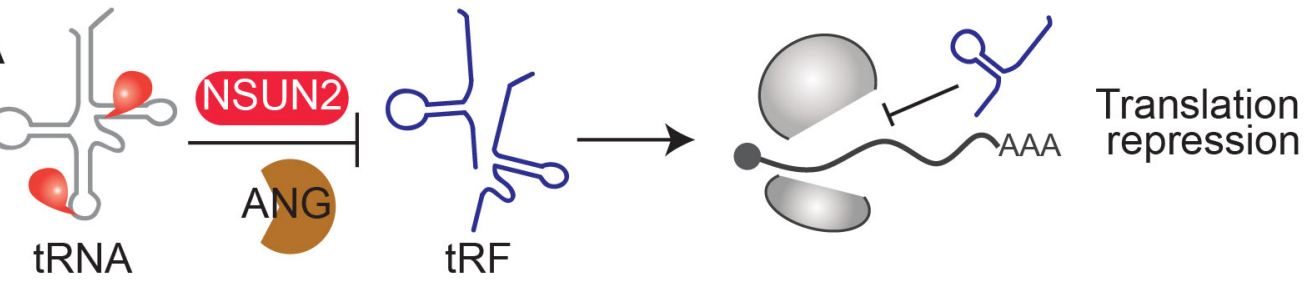

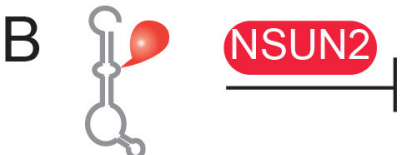

Vault RNA

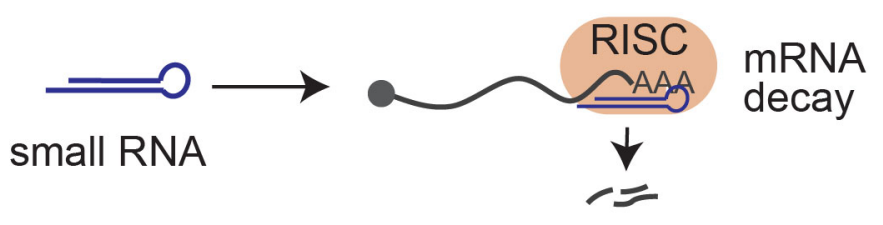

C
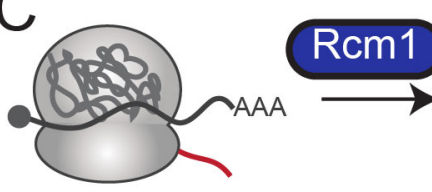

Reprogrammed

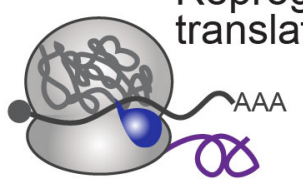

D Mitochondrion

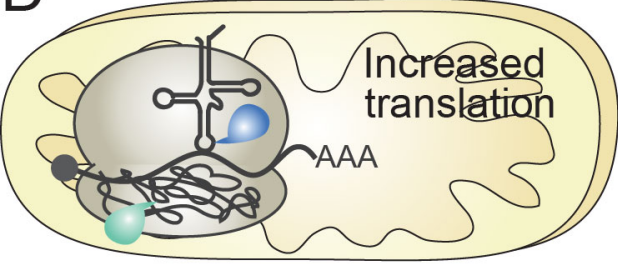

E

Nucleus

Polll Increased

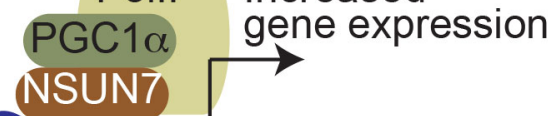

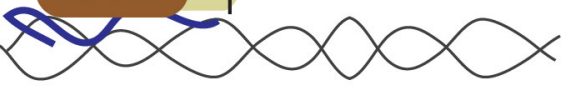

$\mathrm{F}$

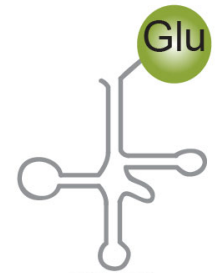

CUC

I I

GAC

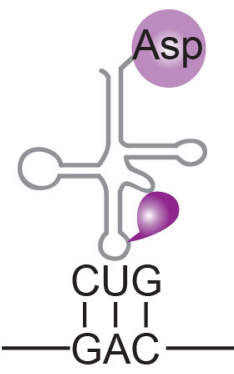

Colour code methylation

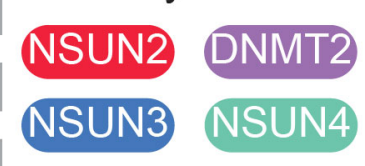

\section{Rcm1}

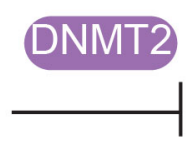


Figure 4

\section{A}

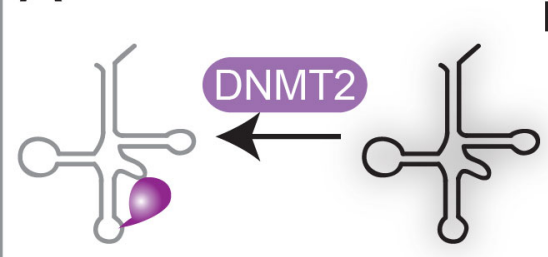

Heat-shock

B

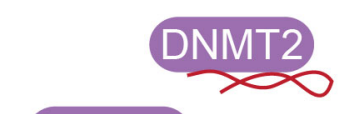

DNMT2

12 DNMT2

Anti-viral defence

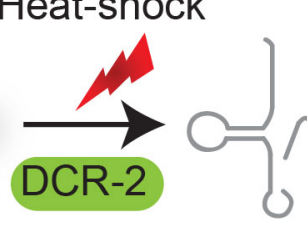

tRFs

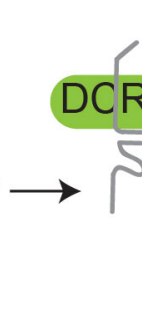

\section{R-2}

DCR-2

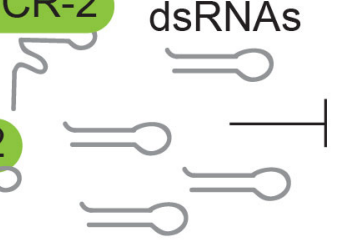

ARGO

DCR-2

no siRNA/

miRNA production

C
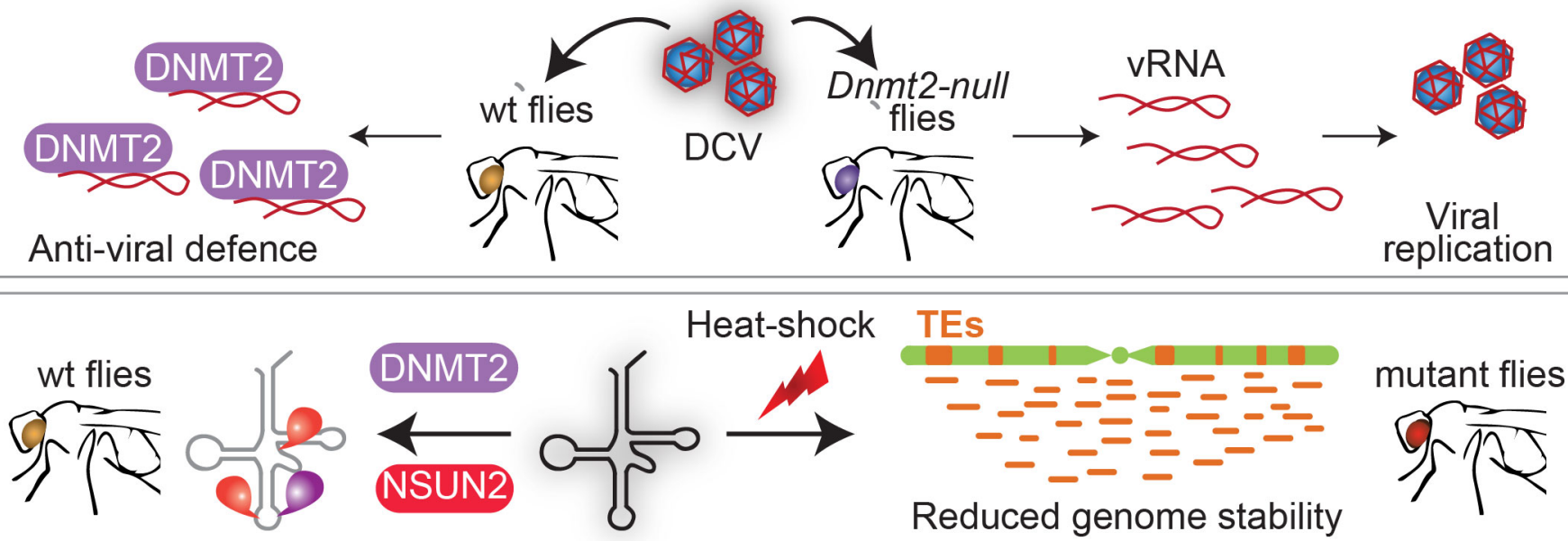

Heat-shock TEs

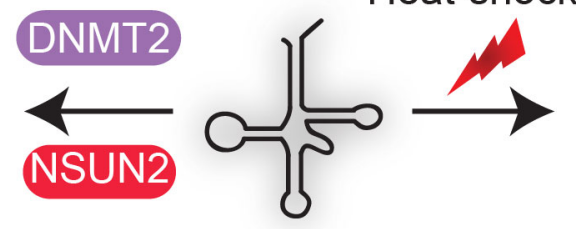

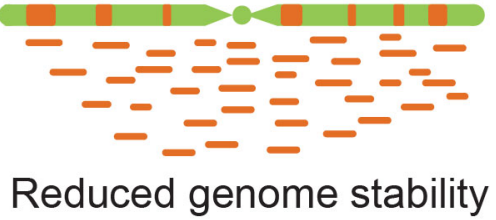

mutant flies

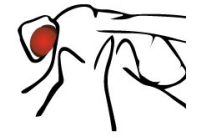


Figure 5
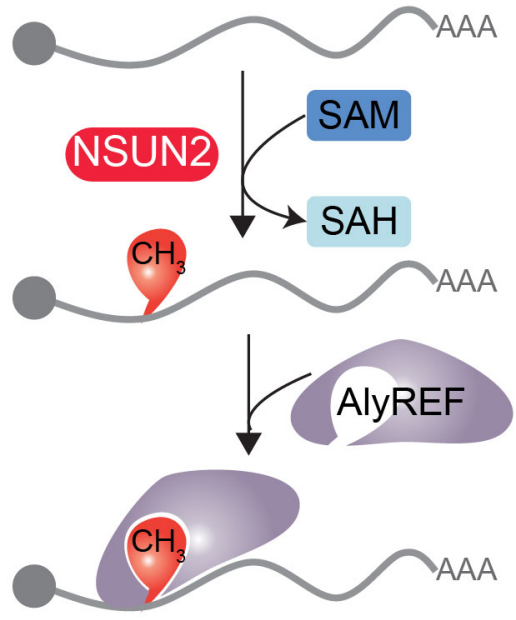

Nuclear export $\mid \begin{array}{r}\text { nucleus } \\ \downarrow \text { cytoplasm }\end{array}$

$\mathrm{CH}_{3}$ 
Figure 6

Cytosine
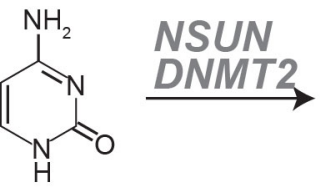

5-methylcytosine 5-hydroxy methyl-cytosine

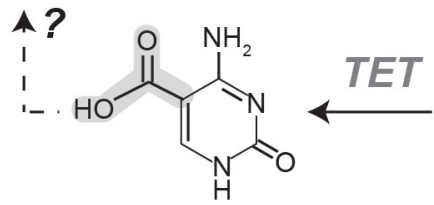

5-carboxy-cytosine

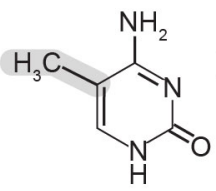

TET (mRNA)

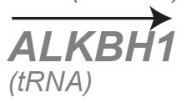

$\mathrm{OH} \mathrm{NH}_{2}$
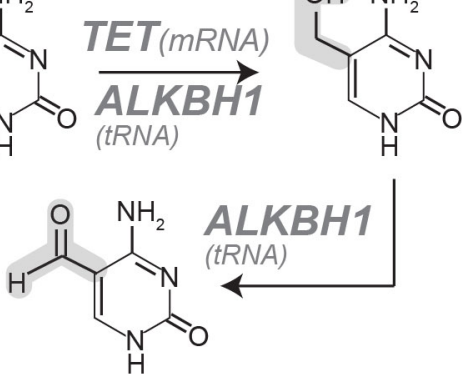

5-formyl-cytosine 